\title{
Protein methionine oxidation augments reperfusion injury in acute ischemic stroke
}

\author{
Sean X. Gu, llya O. Blokhin, Katina M. Wilson, Nirav Dhanesha, Prakash Doddapattar, \\ Isabella M. Grumbach, Anil K. Chauhan, and Steven R. Lentz \\ Department of Internal Medicine, University of lowa Carver College of Medicine, lowa City, lowa, USA.
}

\begin{abstract}
Reperfusion injury can exacerbate tissue damage in ischemic stroke, but little is known about the mechanisms linking ROS to stroke severity. Here, we tested the hypothesis that protein methionine oxidation potentiates NF- $\mathrm{KB}$ activation and contributes to cerebral ischemia/reperfusion injury. We found that overexpression of methionine sulfoxide reductase $A$ (MsrA), an antioxidant enzyme that reverses protein methionine oxidation, attenuated ROS-augmented NF- $\kappa$ B activation in endothelial cells, in part, by protecting against the oxidation of methionine residues in the regulatory domain of calcium/calmodulin-dependent protein kinase II (CaMKII). In a murine model, MsrA deficiency resulted in increased NF-кB activation and neutrophil infiltration, larger infarct volumes, and more severe neurological impairment after transient cerebral ischemia/reperfusion injury. This phenotype was prevented by inhibition of NF-KB or CaMKII. MsrA-deficient mice also exhibited enhanced leukocyte rolling and upregulation of E-selectin, an endothelial NF-кB-dependent adhesion molecule known to contribute to neurovascular inflammation in ischemic stroke. Finally, bone marrow transplantation experiments demonstrated that the neuroprotective effect was mediated by MsrA expressed in nonhematopoietic cells. These findings suggest that protein methionine oxidation in nonmyeloid cells is a key mechanism of postischemic oxidative injury mediated by NF- $\kappa B$ activation, leading to neutrophil recruitment and neurovascular inflammation in acute ischemic stroke.
\end{abstract}

Conflict of interest: The authors have declared that no conflict of interest exists.

Submitted: January 12, 2016

Accepted: April 19, 2016

Published: May 19, 2016

Reference information:

JCI Insight. 2016;1(7):e86460.

doi:10.1172/ji.insight.86460.

\section{Introduction}

Stroke is a leading cause of long-term disability and mortality worldwide (1). Acute ischemic stroke is characterized by rapid loss of neurological function as a result of insufficient blood flow to affected brain regions. Current treatment is designed to quickly restore blood flow through direct endovascular recanalization or the use of thrombolytic therapy (2). Paradoxically, however, cerebral vessel recanalization itself can cause further damage to brain tissue via reperfusion injury (3). During reestablishment of blood flow, restoration of oxygenated blood to ischemic regions induces pathways that produce inflammatory cytokines and ROS (4).

Dysregulated production of ROS in the cerebral vasculature can lead to wide-ranging biochemical and cellular effects, including oxidation of regulatory proteins, cellular cytotoxicity, and inflammatory responses that exacerbate tissue damage (4). Several studies have suggested that ROS exacerbate stroke severity and adverse neurological outcomes in experimental models of transient cerebral ischemia (5-8). ROS have been shown to regulate redox-sensitive cellular responses, including the NF- $\kappa \mathrm{B}$ transcription factor pathway that is a key mediator of postischemic neurovascular inflammation (9). The NF- $\kappa B$ pathway is activated during the acute response to cerebral ischemia/reperfusion injury, and inhibition of $\mathrm{NF}-\mathrm{\kappa B}$ activation is protective (10). The NF-kB pathway is known to be sensitive to modulation by ROS $(11,12)$. Paradoxically, ROS have been reported to both activate and repress NF-kB-dependent gene expression, depending on the cell type and signaling context (13). The precise molecular mechanisms by which ROS regulates neurovascular $\mathrm{NF}-\kappa \mathrm{B}$ activation in the context of ischemia/reperfusion injury are not well understood.

Protein methionine oxidation, a reversible posttranslational protein modification, recently has emerged as a common redox regulatory mechanism in the vascular system (14). Oxidation of protein methionine residues by ROS can alter the structure and function of key vascular proteins, potentially contributing to vascular disease. For example, recent studies have demonstrated that methionine sulfoxide reductase $\mathrm{A}(\mathrm{Msr} \mathrm{A})$, an intracellular enzyme that reverses protein methionine oxidation, can protect 

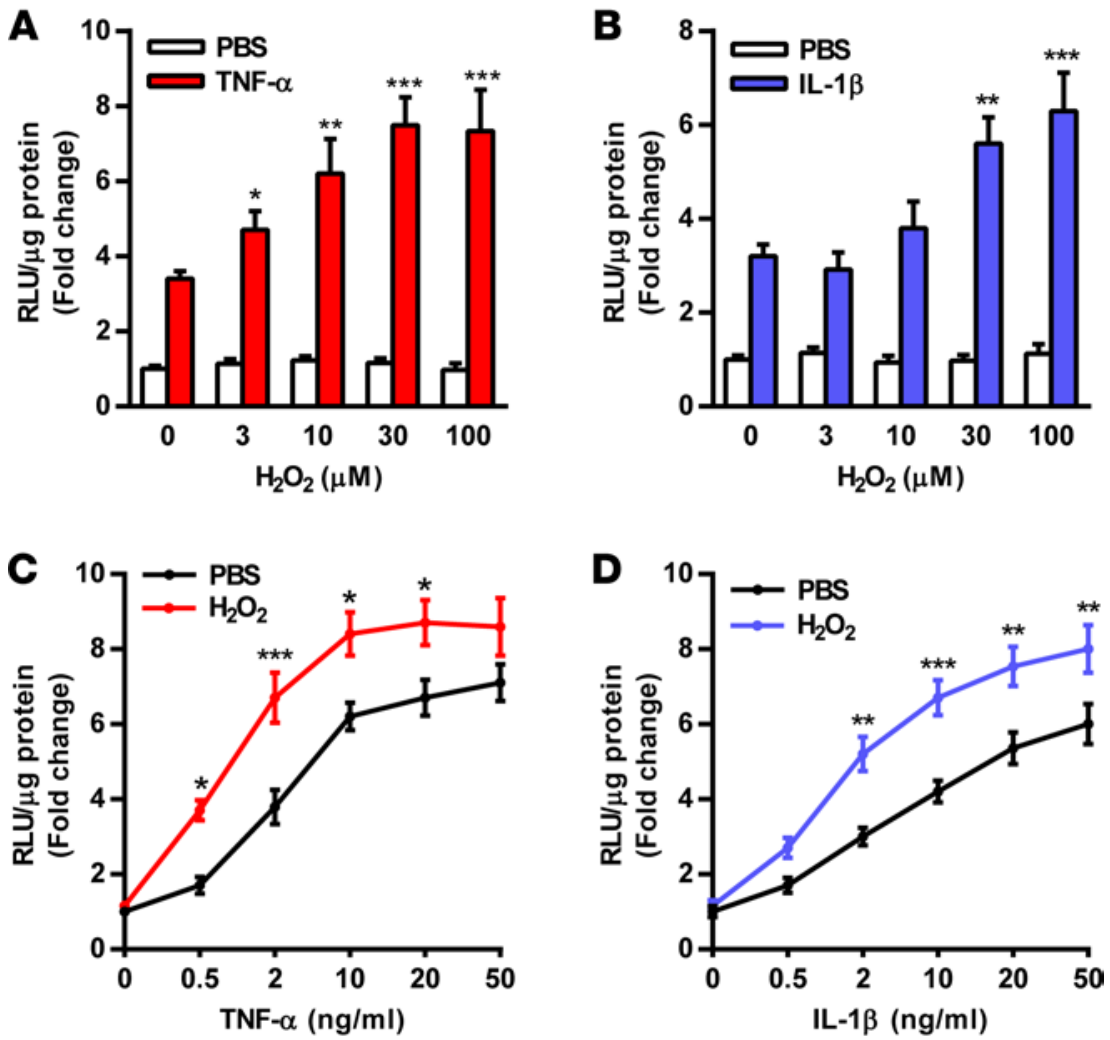

Figure 1. Activation of NF- $\kappa B$ is potentiated by $\mathrm{H}_{2} \mathrm{O}_{2}$ in endothelial cells. HUVECs were infected with an adenoviral NF- $\kappa B$ reporter, Ad-NF- $\kappa B-L u c$ (MOI $=1,000$ particles/cell). At 40 hours after infection, cells were stimulated with $2 \mathrm{ng} / \mathrm{ml}$ of (A) TNF- $\alpha$ or (B) IL-1 $\beta$ in the presence of the indicated concentrations of $\mathrm{H}_{2} \mathrm{O}_{2}$. Alternatively, cells were stimulated with $30 \mu \mathrm{M} \mathrm{H}_{2} \mathrm{O}_{2}$ in the presence of the indicated concentrations of (C) TNF- $\alpha$ or (D) IL-1 $1 \beta$. After 4 hours, NF- $\kappa B$ activity was assessed by a luciferase enzymatic assay. Results are normalized for total protein and for luciferase activity in PBS-treated control cells. Data are expressed as mean RLU \pm SEM $(n=5-6)$. ${ }^{*} P<0.05$, ${ }^{* *} P<0.01$, ${ }^{* *} P<0.001 \mathrm{vs.} \mathrm{control,} \mathrm{(A} \mathrm{and} \mathrm{B)} \mathrm{2-way} \mathrm{ANOVA} \mathrm{with} \mathrm{Dunnett's} \mathrm{multiple}$ comparisons test and (C and $\mathbf{D})$ 2-way ANOVA with Sidak's multiple comparisons test.

from atherosclerosis and neointimal hyperplasia in mice (15-17). MsrA also protects from cardiac and renal ischemia/reperfusion injury in mouse models $(18,19)$. Moreover, GWAS have identified a polymorphism in the MsrA locus that is associated with increased coronary vascular events in humans $(20$, 21). MsrA has been reported to protect from neurovascular inflammation in a model of sepsis (22), but the potential role of MsrA and protein methionine oxidation in the postischemic inflammation of stroke has not been well studied.

Within this framework, we utilized a mouse model of MsrA deficiency to test the hypothesis that protein methionine oxidation potentiates NF- $\mathrm{B}$ activation and contributes to cerebral ischemia/reperfusion injury. Our results demonstrate that MsrA protects from ROS-augmented NF- $\mathrm{BB}$ activation in endothelial cells and that the endogenous murine $M s r A$ gene protects from NF- $\mathrm{kB}$-dependent cerebral ischemia/ reperfusion injury in vivo. These findings suggest that protein methionine oxidation is a reversible process that mediates postischemic neurovascular inflammation and critically contributes to brain injury in acute ischemic stroke.

\section{Results}

Activation of $\mathrm{NF}-\kappa \mathrm{B}$ is augmented by $\mathrm{H}_{2} \mathrm{O}_{2}$ in endothelial cells. To define the effects of ROS and inflammatory cytokines on NF- $\kappa B$ activation, cultured HUVECs were infected with an adenoviral NF- $\mathrm{B}$ reporter construct (Ad-NF-kB-luc) and exposed to hydrogen peroxide $\left(\mathrm{H}_{2} \mathrm{O}_{2}\right)$ in the presence or absence of the cytokines TNF- $\alpha$ or IL-1 $\beta$. Luciferase activity was assessed as a measure of NF- $\kappa$ B transcriptional activity (Figure 1). Treatment with $\mathrm{H}_{2} \mathrm{O}_{2}$ alone had no significant effect on $\mathrm{NF}-\kappa \mathrm{B}$ activation; however, $\mathrm{H}_{2} \mathrm{O}_{2}$ potentiated NF- $\kappa \mathrm{B}$ activation in a dose-dependent manner in the presence of either TNF- $\alpha$ or IL- $1 \beta$, with $>50 \%$ increases in NF- $\kappa \mathrm{B}$ activity observed with $30 \mu \mathrm{M}$ or $100 \mu \mathrm{M} \mathrm{H}_{2} \mathrm{O}_{2}(P<0.01)$ (Figure $1, \mathrm{~A}$ and B). NF- $\kappa \mathrm{B}$ 

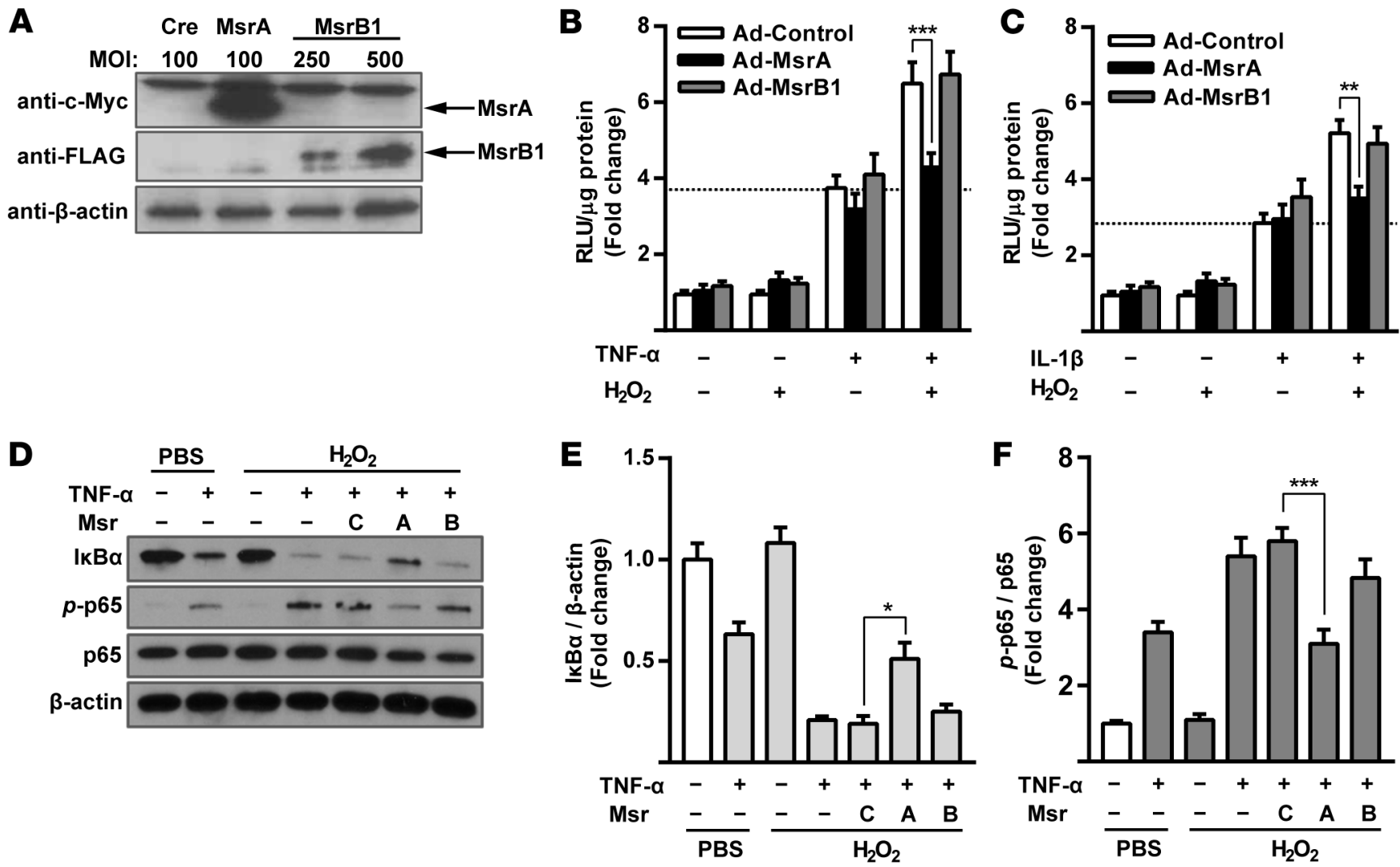

Figure 2. MsrA protects against $\mathbf{H}_{2} \mathbf{O}_{2}$-augmented activation of NF- $\kappa B$ in endothelial cells. HUVECs were coinfected with Ad-NF- $\kappa B$-Luc together with adenoviruses overexpressing human MsrA (Ad-MsrA-Myc), MsrB1 (Ad-MsrB1-FLAG), or Cre (Ad-Control). (A) Expression of MsrA and MsrB1 was confirmed by immunoblotting using anti-Myc and anti-FLAG antibodies, respectively, with $\beta$-actin as a loading control. At 40 hours after infection, cells were stimulated with $2 \mathrm{ng} / \mathrm{ml}$ of (B) TNF- $\alpha$ or (C) IL-1 $\beta$ in the presence ( + ) or absence (-) of $\mathrm{H}_{2} \mathrm{O}_{2}(30 \mu \mathrm{M})$ as indicated. After 4 hours, cell lysates were isolated and assayed for NF- $\kappa B$ activity by a luciferase enzymatic assay. The dotted line indicates the level of NF- $\kappa B$ activation with TNF- $\alpha$ or IL- $1 \beta$ in the absence of $\mathrm{H}_{2} \mathrm{O}_{2}$. Results are expressed as mean RLU $\pm \mathrm{SEM}$ after normalization for total protein and for luciferase activity in PBS-treated controls $(n=6)$. (D) Representative immunoblot of NF- $\kappa B$ regulatory proteins in lysates of TNF- $\alpha$ - and/or $\mathrm{H}_{2} \mathrm{O}_{2}$-treated cells. Levels of (E) I $\mathrm{kB} \alpha$ and $(\mathbf{F})$ phosphorylated-p65 quantified by densitometry and normalized for $\beta$-actin and $p 65$, respectively $(n=4)$. Results are reported as relative change versus PBS-treated control and expressed as mean \pm SEM. ${ }^{*} P<0.05$; ${ }^{*} P<0.01 ;{ }^{* *} P<0.001$, (B and $\mathbf{C}$ ) 2-way ANOVA with Tukey's multiple comparisons test and (E and $\mathbf{F}$ ) 1 -way ANOVA with Tukey's multiple comparisons test.

modulation by $\mathrm{H}_{2} \mathrm{O}_{2}$ was observed over a wide range of concentrations of TNF- $\alpha$ or IL-1 $\beta$ (Figure $1, \mathrm{C}$ and D). Similar findings were observed with other ROS, including $\mathrm{HOCl}$ and peroxynitrite (data not shown).

MsrA protects against $\mathrm{H}_{2} \mathrm{O}_{2}$-augmented activation of $\mathrm{NF}-\kappa \mathrm{B}$ in endothelial cells. To test the hypothesis that the NF- $\mathrm{BB}$ pathway is regulated by protein methionine oxidation, HUVECs were infected with adenoviruses overexpressing either human MsrA (Ad-MsrA-Myc) or MsrB1 (Ad-MsrB1-FLAG), both of which encode the major Msr gene products that localize in the cytoplasm and nucleus (23). Expression of Myctagged MsrA and FLAG-tagged MsrB1 was confirmed by immunoblotting (Figure 2A). Using an adenoviral NF- $\kappa$ B reporter (Ad-NF- $\kappa B-l u c$ ), we found that $\mathrm{H}_{2} \mathrm{O}_{2}$-augmented $\mathrm{NF}-\kappa \mathrm{B}$ activation was prevented by overexpression of MsrA but not MsrB1 in the presence of either TNF- $\alpha$ (Figure 2B) or IL-1 $\beta$ (Figure 2C). Immunoblot analysis of $\mathrm{NF}-\kappa \mathrm{B}$ regulatory proteins confirmed that MsrA, but not MsrB1, prevented the degradation of $\mathrm{I} \kappa \mathrm{B} \alpha$ and decreased the phosphorylation of p65 induced by $\mathrm{H}_{2} \mathrm{O}_{2}$ in the presence of TNF- $\alpha$

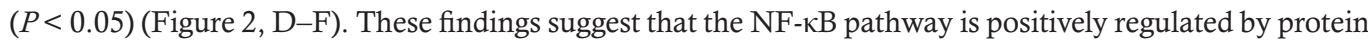
methionine oxidation in endothelial cells.

CaMKII Met281/282 oxidation contributes to NF- $\kappa B$ activation in endothelial cells. The NF- $\kappa B$ pathway is regulated by upstream protein kinases, including calcium/calmodulin-dependent protein kinase II (CaMKII), a redox-sensitive serine/threonine kinase that has been shown to positively regulate $\mathrm{NF}-\mathrm{\kappa B}$ activation in myocardial ischemia/reperfusion injury (24-27). Treatment of HUVECs with a small-molecule CaMKII inhibitor (KN-93) significantly diminished the stimulatory effects TNF- $\alpha$ and $\mathrm{H}_{2} \mathrm{O}_{2}$ on NF- $\mathrm{\kappa B}$ activation, as demonstrated by luciferase activity $(P<0.05$ vs. inactive analog KN-92 or PBS control) (Figure 3A). Simi- 
A
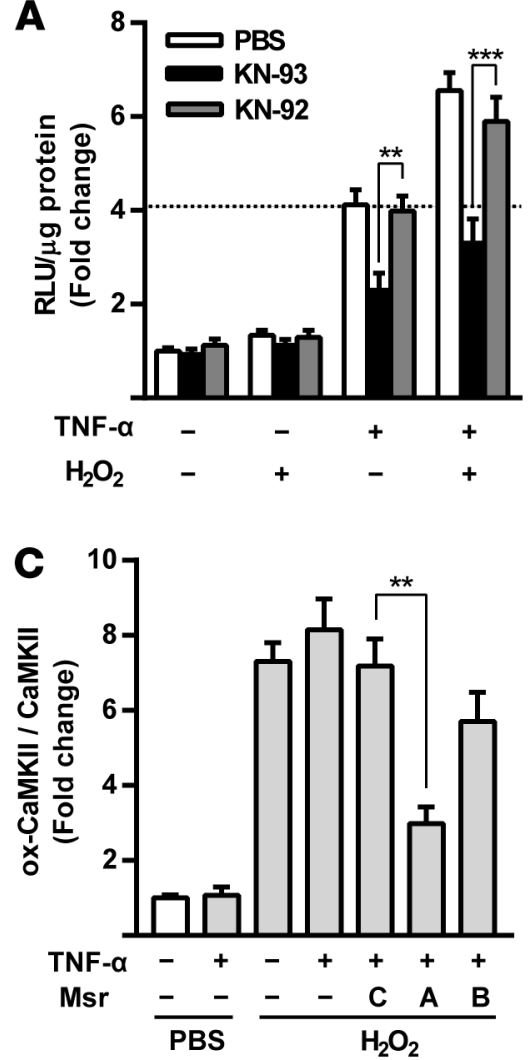

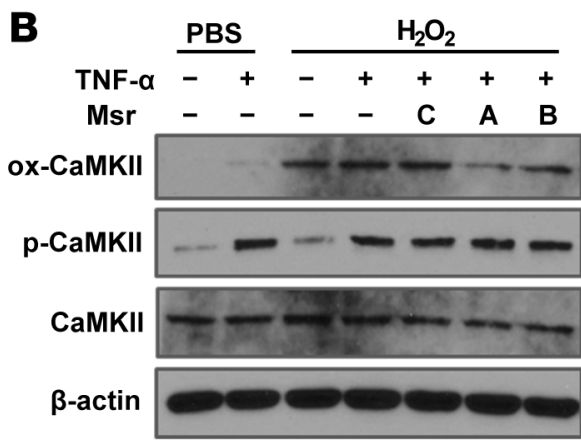

D

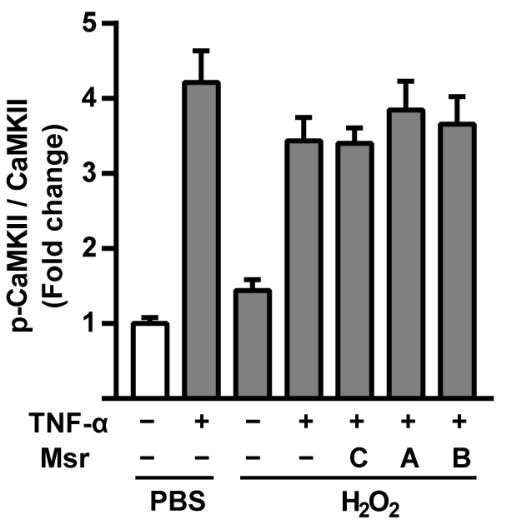

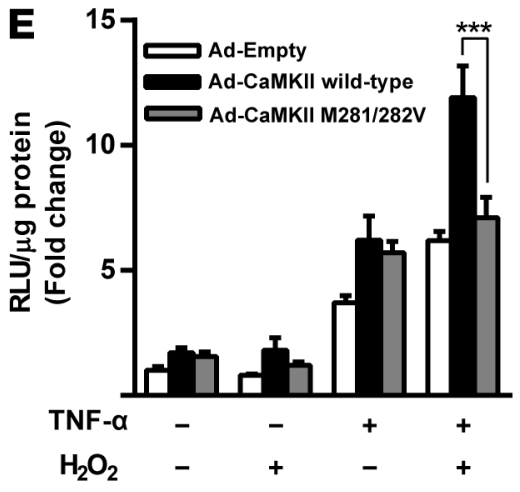

Figure 3. CaMKII Met-281/282 oxidation contributes to NF-KB activation in endothelial cells. (A) HUVECs were treated with $1 \mu \mathrm{M}$ KN-93, KN-92, or PBS control in the presence (+) or absence (-) of TNF- $\alpha$ or $\mathrm{H}_{2} \mathrm{O}_{2}$. NF- $\mathrm{kB}$ activity was assessed by luciferase enzymatic assay. Results are normalized for total protein and for luciferase activity in PBS-treated control cells. Data are expressed as mean RLU \pm SEM $(n=5)$. The dotted line indicates the level of NF- $\mathrm{KB}$ activation with TNF- $\alpha$ in the absence of $\mathrm{H}_{2} \mathrm{O}_{2}$. (B) Representative immunoblot of CaMKII Met281/282 oxidation (ox-CaMKII) and CaMKII Thr287 phosphorylation ( $p$-CaMKII) in lysates of TNF- $\alpha$ and/or $\mathrm{H}_{2} \mathrm{O}_{2}$ treated cells that were infected with adenoviruses overexpressing MsrA, MsrB1, or Cre control. Levels of (C) ox-CaMKII and (D) p-CaMKII were quantified by densitometry and normalized for total CaMKII $(n=3)$. $\beta$-Actin was used as a loading control. Results are reported as relative change versus PBS-treated control and expressed as mean \pm SEM. (E) NF- $\kappa B$ activity assessed by luciferase enzymatic activity in HUVECs infected with adenoviruses overexpressing WT CaMKII, CaMKII M281/282V, or empty control in the presence or absence of TNF- $\alpha$ or $\mathrm{H}_{2} \mathrm{O}_{2}$. Results are normalized for total protein and for luciferase activity in PBS-treated control cells. Data are expressed as mean RLU \pm SEM $(n=5)$. All concentrations of TNF- $\alpha$ are $2 \mathrm{ng} / \mathrm{ml}$ and concentrations of $\mathrm{H}_{2} \mathrm{O}_{2}$ are $30 \mu \mathrm{M}$ unless otherwise indicated. ${ }^{* *} P<0.01$; ${ }^{* *} P<0.001$, (A and E) 2-way ANOVA with Tukey's multiple comparisons test and (C and $\mathbf{D}$ ) 1-way ANOVA with Tukey's multiple comparisons test.

lar to previous findings in cardiomyocytes (24), treatment of HUVECs with $\mathrm{H}_{2} \mathrm{O}_{2}$ caused protein methionine oxidation of CaMKII at Met281/282 (detected by an oxidation-specific CaMKII antibody; ref. 24) in either the presence or absence of TNF- $\alpha$, whereas TNF- $\alpha$ caused phosphorylation of CaMKII at Thr287 that was largely unaffected by $\mathrm{H}_{2} \mathrm{O}_{2}$ (Figure 3, B-D). The effect of $\mathrm{H}_{2} \mathrm{O}_{2}$, but not TNF- $\alpha$, was prevented by adenoviral overexpression of MsrA. To confirm that the stimulatory effect of $\mathrm{H}_{2} \mathrm{O}_{2}$ on NF- $\mathrm{kB}$ activation in endothelial cells was mediated by protein methionine oxidation of CaMKII Met281/282, HUVECs were infected with adenoviral constructs to overexpress either WT CaMKII or an oxidation-resistant tandem methionine mutant (CaMKII M281/282V). Overexpression of WT CaMKII increased NF-kB activity by $80 \%$ in the presence of TNF- $\alpha$ and $\mathrm{H}_{2} \mathrm{O}_{2}$, and overexpression of CaMKII M281/282V completely prevented $\mathrm{H}_{2} \mathrm{O}_{2}$-augmented NF-kB activation ( $P<0.01$ vs. WT CaMKII) (Figure $3 \mathrm{E}$ ). These results suggest that $\mathrm{H}_{2} \mathrm{O}_{2}$-augmented NF- $\mathrm{kB}$ activation in endothelial cells is mediated by protein methionine oxidation of CaMKII Met281/282.

MsrA deficiency enhances NF- $\kappa B$ activation in vivo. To assess the role of methionine oxidation on NF- $\mathrm{KB}$ activation in vivo, we utilized a line of transgenic NF-KB-reporter mice (referred to as $H L L$ mice) that ubiquitously express Photinus luciferase under the control of an NF-kB-dependent promoter (28). HLL mice were crossbred with MsrA-deficient $\left(M s r A^{-/}\right)$mice to generate a double-transgenic strain $\left(M s r A^{-/-} H L L\right.$ mice). This model provides an in vivo system to analyze NF-kB activity by measuring luciferase activity in 
A Lung

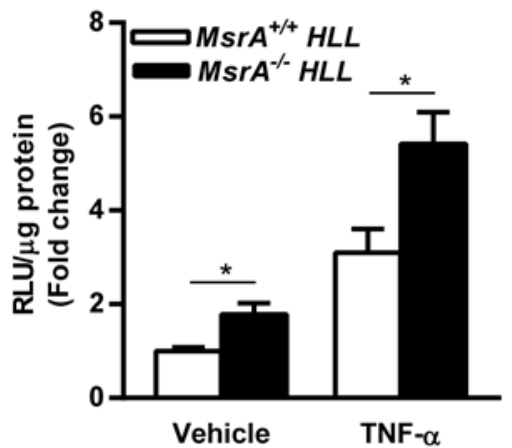

B Aorta

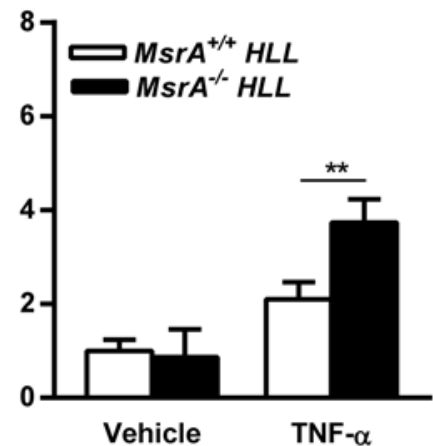

\section{Carotid}

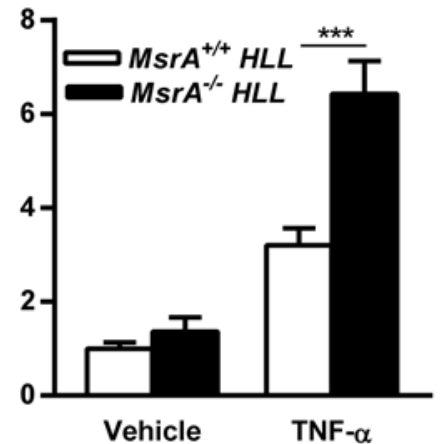

D

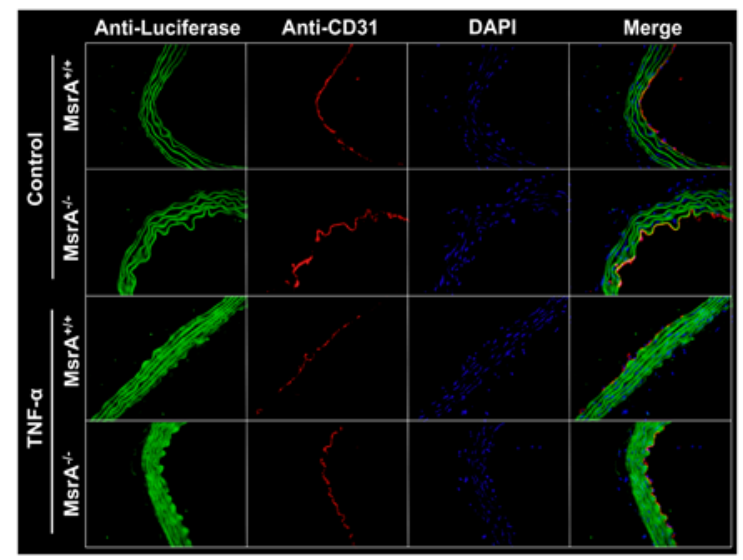

E

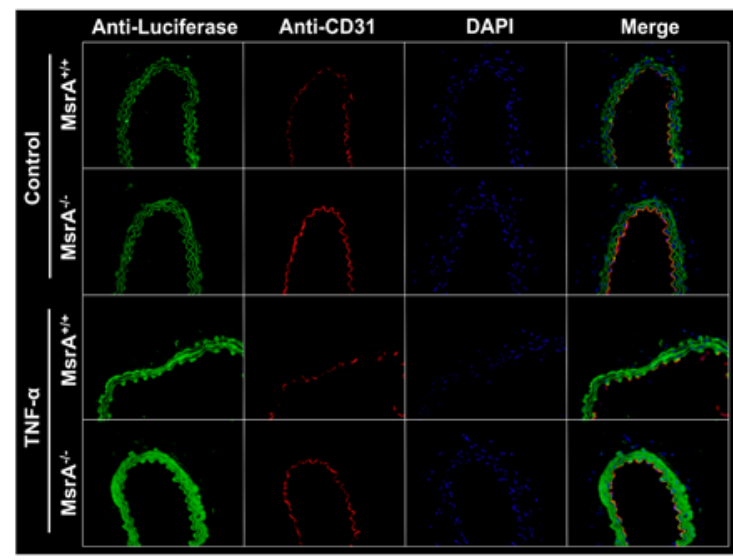

Figure 4. MsrA deficiency enhances vascular NF- $\mathbf{B}$ activation in vivo. NF- $\kappa$ B activity was assessed by luciferase enzymatic assay in the (A) lungs, (B) aortas, and (C) carotid arteries of MsrA ${ }^{-/-} H L L$ or MsrA ${ }^{+/+} H L L$ mice 4 hours after treatment with TNF- $\alpha$ (1 mg/kg i.p.) or vehicle (PBS). Results were normalized for total protein and luciferase activity in vehicle-treated $M s r A^{-/-} H L L$ mice. Data are expressed as mean RLU $\pm S E M\left(n=6\right.$ for each group). ${ }^{*} P<0.05 ;{ }^{*} P<$ $0.01 ;{ }^{* *} P<0.001,2$-way ANOVA with Tukey's multiple comparisons test. Representative immunofluorescence images of cross sections of (D) aortas and (E) carotid arteries from MsrA ${ }^{+/+} H L L$ or $M s r A^{-/-} H L L$ mice 4 hours after treatment with TNF- $\alpha$ (1 mg/kg) or vehicle as indicated. Sections were stained with antibodies to luciferase (green), the endothelial marker CD31 (red), and the nuclear marker DAPI (blue), and then merged. Original magnification, $\times 40$.

the setting of MsrA deficiency. Mice were injected with either TNF- $\alpha$ ( $1 \mathrm{mg} / \mathrm{kg}$ i.p.) or vehicle, and luciferase activity was measured in the lungs, aortas, and carotid arteries after 4 hours. Compared with $M s r A^{+/+}$ $H L L$ mice, $M s r A^{-1-} H L L$ mice exhibited enhanced NF- $\kappa \mathrm{B}$ activity after treatment with $\mathrm{TNF}-\alpha(P<0.05)$ (Figure 4, A-C). In vehicle-treated mice, enhanced NF- $\mathrm{BB}$ activation in $M s r A^{-/-} H L L$ mice was observed only in lungs, compared with that in $M s r A^{+/+} H L L$ mice $(P<0.05)$ (Figure $\left.4 \mathrm{~A}\right)$. Enhanced NF- $\mathrm{kB}$ activation in the aortas and carotid arteries of TNF- $\alpha$-treated $M s r A^{-1-}$ mice was confirmed by immunofluorescence imaging of the luciferase reporter protein (Figure 4, D and E). Colocalization of luciferase with an endothelial marker (CD31) indicates that NF- $\mathrm{B}$ activation was enhanced in the endothelium (intima) as well as in the media of the aorta and carotid artery.

To further examine the role of methionine oxidation in endothelial NF- $\mathrm{KB}$ activation, we isolated brain microvascular endothelial cells (BMVECs) from $M s r A^{+/+} H L L$ and $M s r A^{-/} H L L$ mice by fluorescence-activated cell sorting (Supplemental Figure 1, A and B; supplemental material available online with this article; doi:10.1172/jci.insight.86460DS1). We found that $M s r A^{-/-}$BMVECs have enhanced NF- $\mathrm{kB}$ activation compared with $M s r A^{+/+}$BMVECs (Supplemental Figure 1C). Treatment with TNF- $\alpha$ increased NF- $\kappa B$ activation in both $\mathrm{Msr}^{-/-}$and $M s r A^{+/+}$BMVECs. Addition of $\mathrm{H}_{2} \mathrm{O}_{2}$ enhanced NF- $\kappa \mathrm{B}$ activation in $M s r A^{+/+}$ BMVECs but did not further enhance NF- $\kappa \mathrm{B}$ activation in $M s r A^{-/}$BMVECs, suggesting that NF- $\mathrm{kB}$ is maximally activated in TNF- $\alpha$-stimulated $M s r A^{-/-}$BMVECs.

$M s r A^{-1-}$ mice exhibit increased susceptibility to cerebral ischemia/reperfusion injury. To define the role of methionine oxidation in ischemic stroke, we induced focal cerebral ischemia using a transient middle cerebral artery occlusion (tMCAO) model of ischemia/reperfusion injury. Susceptibility to tMCAO 
A

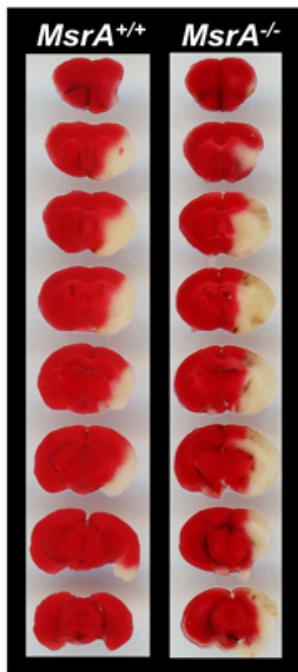

B

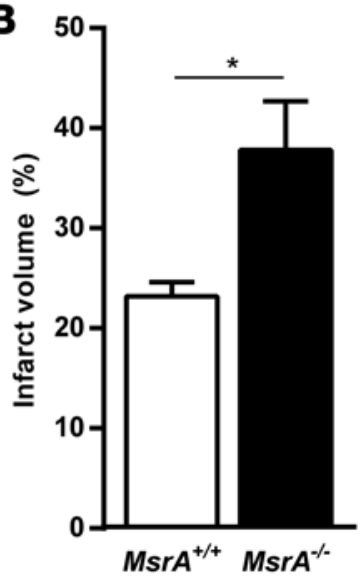

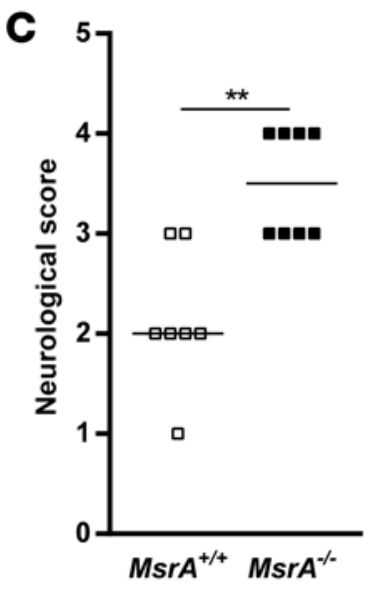

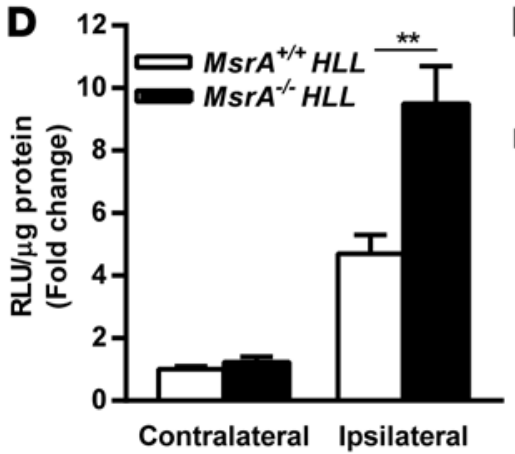

$\mathbf{E}$

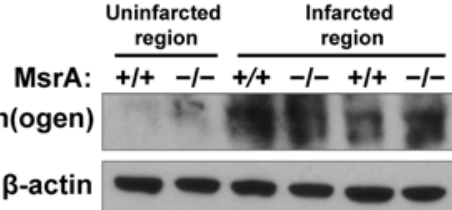

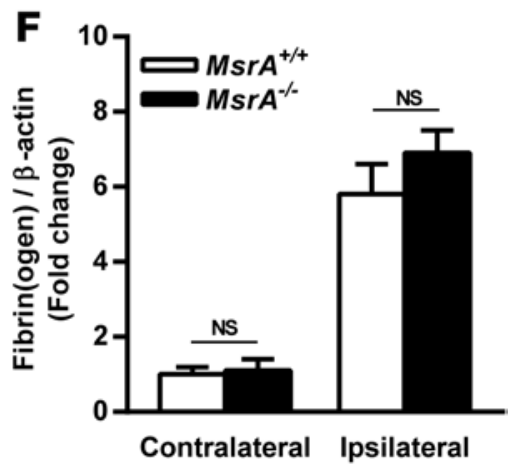

Figure 5. MsrA ${ }^{-/-}$mice exhibit increased susceptibility to cerebral ischemia/reperfusion injury. (A) Representative 2,3,5-triphenyltetrazolium chloride (TTC) staining of serial coronal sections of $\mathrm{MsrA}^{+/+}$or $\mathrm{MsrA}^{-/-}$mice 24 hours after tMCAO. Viable tissue was stained red, whereas the infarcted area remained unstained (white). (B) Corrected mean infarct volume of each group expressed as mean \pm SEM ( $n=7-8$ mice/group). ${ }^{*} P<0.05,2$-sided, unpaired Student's $t$ test. (C) Neurological score of each group expressed as scatter plots with horizontal line depicting the median. ${ }^{* *} P<0.01$, Mann-Whitney $U$ test. (D) NF- $\kappa B$ activity was assessed by luciferase enzymatic assay in the ipsilateral infarcted hemisphere and the contralateral uninfarcted hemisphere of $\mathrm{MsrA}^{+/+} \mathrm{HLL}(n=5)$ or $\mathrm{Msr}^{-1-} \mathrm{HLL}(n=6)$ mice 24 hours after tMCAO. Results were normalized for total protein and luciferase activity in PBS-treated $\mathrm{MsrA}^{+/+} H L L$ mice. Data are represented as mean RLU $\pm \mathrm{SEM}$. ${ }^{* *} P<0.01$, 2-way ANOVA with Tukey's multiple comparisons test. (E) Representative Western blot of fibrin/fibrinogen [fibrin(ogen)] in brain homogenates of $\mathrm{MsrA}^{+/+}$or $\mathrm{Msr}^{-/-}$mice after tMCAO. (F) Levels of fibrin(ogen) in the infarcted and uninfarcted regions were quantified by densitometry and normalized for $\beta$-actin. Results are reported as mean \pm SEM $(n=4)$. Two-way ANOVA with Tukey's multiple comparisons test.

was assessed by measuring infarct volume and neurological deficits after 1 hour of ischemia followed by 24 hours of reperfusion. Laser Doppler flowmetry was performed to confirm that regional cerebral blood flow was reduced by greater than $80 \%$ compared with baseline during the ischemic phase (data not shown). No gross differences in cerebrovascular anatomy were observed between $\mathrm{Msr}^{+/+}$and $\mathrm{MsrA}^{-/}$ mice (Supplemental Figure 2). Compared with $\mathrm{Msr}^{+/+}$mice, $\mathrm{Msr}^{-/-}$mice had 50\% larger cerebral infarct volumes after tMCAO $(P<0.05)$ (Figure 5, A and B). $\mathrm{Msr}^{-/-}$mice also had more severe motor deficits than WT mice, including neurological deficits, such as head tilt and barrel rolling, that were absent in $\mathrm{MsrA}^{+/+}$mice (Figure 5C).

Because previous studies have shown that NF- $\mathrm{KB}$ is a key mediator of postischemic inflammation in ischemic stroke (10), we next evaluated NF- $\mathrm{kB}$ activation by measuring luciferase activity in $\mathrm{Msr}^{-1}$ $H L L$ mice subjected to tMCAO. We found that NF- $\mathrm{kB}$ activation was greatly enhanced in the ipsilateral infarcted cerebral hemispheres of $M s r A^{-/-} H L L$ mice compared with $M s r A^{+/+} H L L$ mice $(P<0.05)$ (Figure 5D). Because thrombosis also is a major contributing factor to ischemia/reperfusion injury (29), fibrin/ fibrinogen deposition after tMCAO was assessed by immunoblotting. Substantial fibrin/fibrinogen deposition was observed in the infarcted region after tMCAO, whereas fibrin/fibrinogen deposition in the unin- 
A

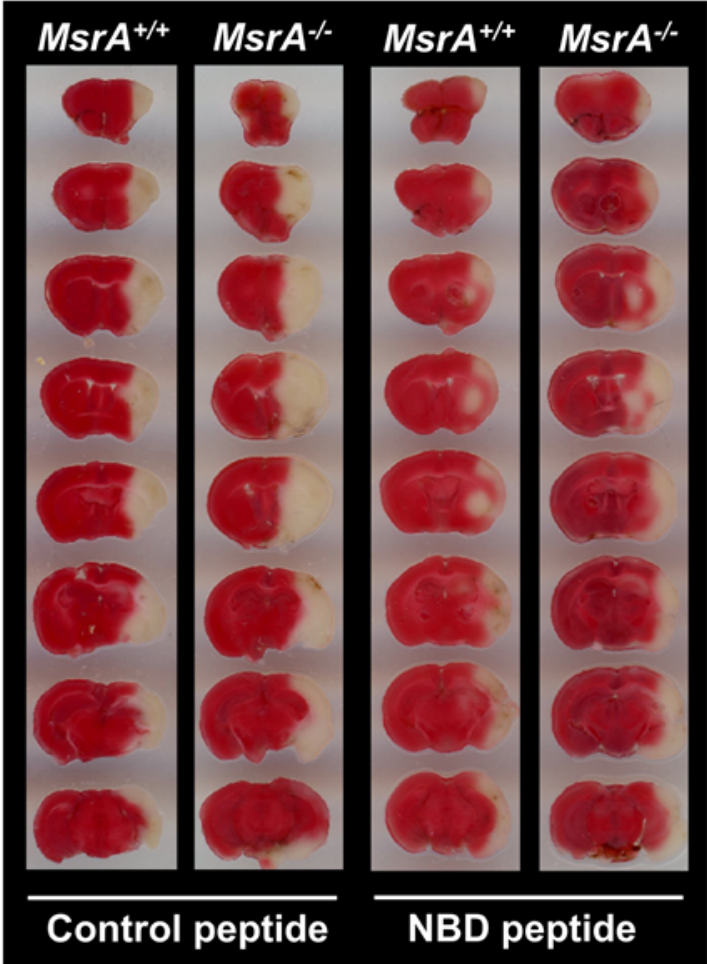

B

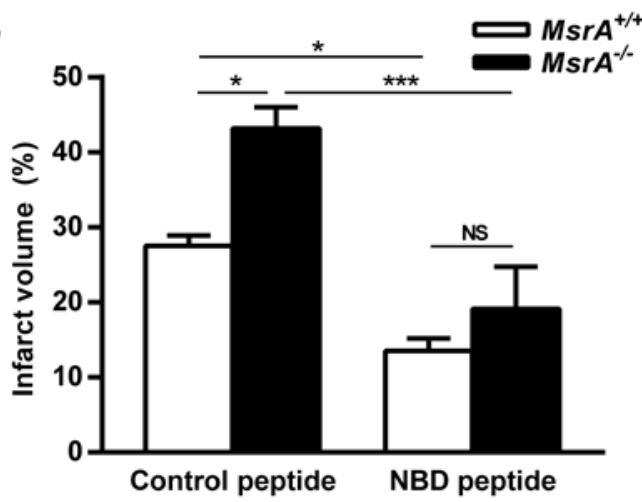

C

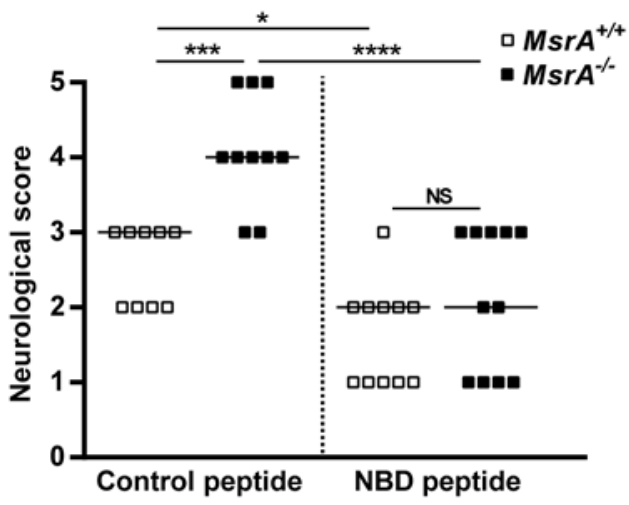

D

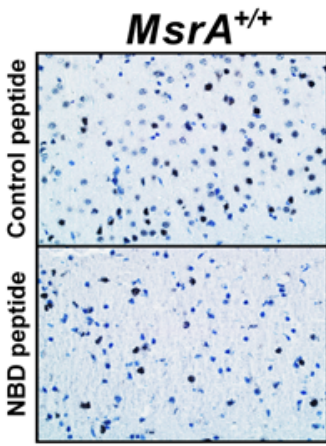

$\mathbf{F}$

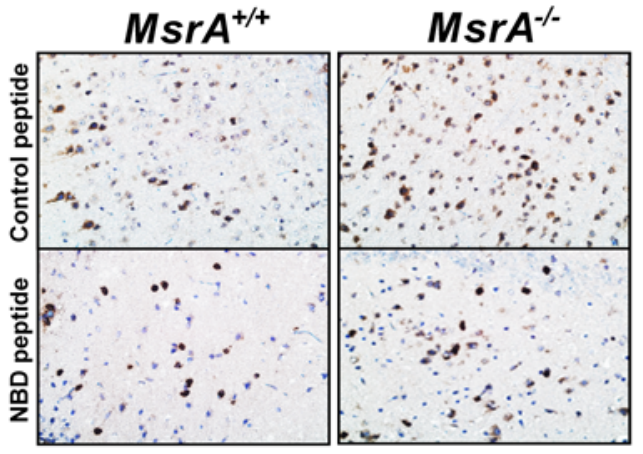

E

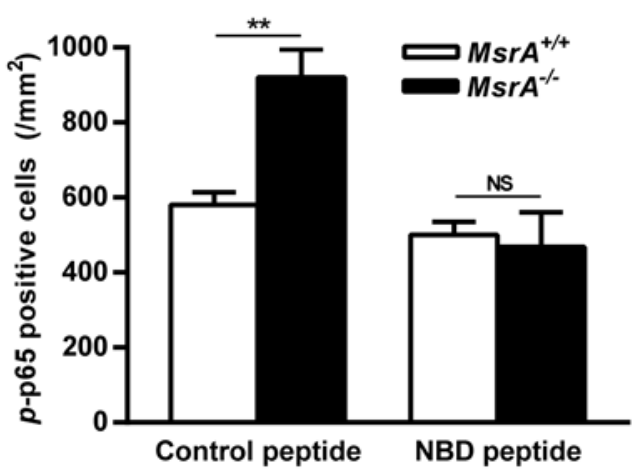

G

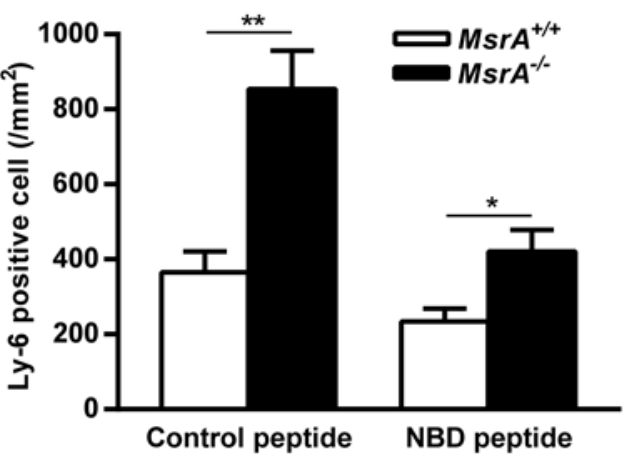

Figure 6. Increased susceptibility of $\mathbf{M s r}^{-/-}$mice to cerebral ischemia/reperfusion injury is NF-kB dependent. (A) Representative 2,3,5-triphenyltetrazolium chloride (TTC) staining of serial coronal sections 24 hours after tMCAO. MsrA ${ }^{+/+}$or MsrA ${ }^{-/-}$mice were treated with control peptide or NBD peptide ( $2 \mathrm{mg} / \mathrm{kg}$ i.p.) 4 hours prior to tMCAO as indicated. (B) Corrected mean infarct volumes of each group expressed as mean \pm SEM ( $n=9-11$ mice/group). ${ }^{*} P<0.05$; ${ }^{* *} P<0.001,2$-way ANOVA with Tukey's multiple comparisons test. (C) Neurological score of each group expressed as scatter plots, with horizontal lines depicting the median. ${ }^{*} P<0.05$; ${ }^{* *} P<0.001$; ${ }^{* * *} P<0.0001$, ANOVA on ranks. (D) Representative sections and (E) quantification of NF- $\kappa B$ activation (phospho-p65-positive cells) in the cerebral infarcted regions following tMCAO. (F) Representative sections and (C) quantification of neutrophils (Ly6 B.2-positive cells) in the cerebral infarcted regions following tMCAO. Sections were counterstained with H\&E. Original magnification, $\times 40$. Data are represented as mean \pm SEM $(n=6-8)$. Mean data for each individual mouse were calculated from 4 coronal sections/mouse (separated by $100 \mu \mathrm{m}) .{ }^{*} P<0.05 ;{ }^{* *} P<0.01,2$-way ANOVA with Tukey's multiple comparisons test. 

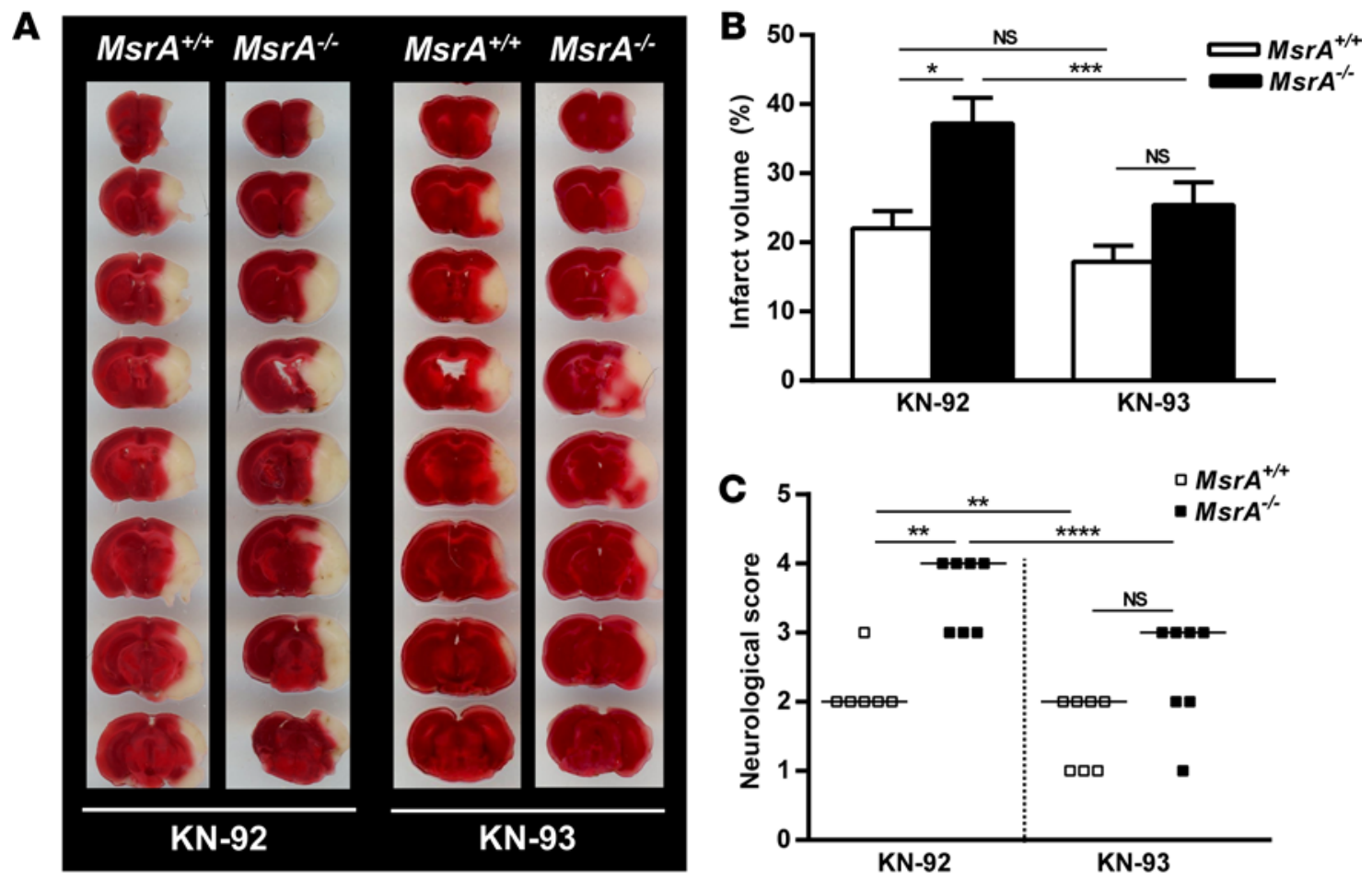

Figure 7. Inhibition of CaMKII protects $\mathbf{M s r A}^{-/-}$mice from cerebral/ischemia reperfusion injury. (A) Representative 2,3,5-triphenyltetrazolium chloride (TTC) staining of serial coronal sections 24 hours after $\mathrm{tMCAO}$. MsrA ${ }^{+/+}$or $\mathrm{MsrA}^{-/-}$mice were treated with CaMKII inhibitor $\mathrm{KN}-93$ (5 mg/kg i.p.) or inactive analog KN-92 4 hours prior to tMCAO as indicated. (B) Corrected mean infarct volumes of each group expressed as mean \pm SEM ( $n=6-7$ mice/group). ${ }^{*} P<$ $0.05 ;{ }^{* *} P<0.001,2$-way ANOVA with Tukey's multiple comparisons test. (C) Neurological score of each group expressed as scatter plots, with horizontal lines depicting the median. ${ }^{* *} P<0.01 ;{ }^{* * *} P<0.0001$, ANOVA on ranks.

farcted region was minimal (Figure 5, E and F). However, no differences in fibrin/fibrinogen deposition between $\mathrm{MsrA}^{-/-}$and $\mathrm{MsrA}^{+/+}$mice were observed. Consistent with these results, susceptibility to both carotid artery thrombosis and inferior vena cava (IVC) thrombosis were comparable between $\mathrm{MsrA}^{-/-}$and $\mathrm{MsrA}^{+/+}$mice (Supplemental Figure 3).

Increased cerebral ischemia/reperfusion injury in $\mathrm{Msr}^{-1-}$ mice is $N F-\kappa B$ dependent. To directly address the

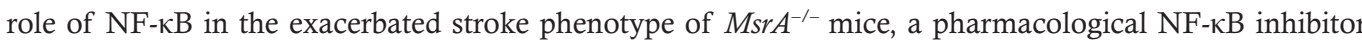
(NBD peptide) (30) or an inactive analog (control peptide) was administered ( $2 \mathrm{mg} / \mathrm{kg}$ i.p.) 4 hours prior to tMCAO. We confirmed that this dose of NBD peptide inhibited NF-kB activity (Supplemental Figure 4). We observed strong neuroprotection with the NBD peptide, which completely eliminated the differences in infarct volume and motor deficits between $\mathrm{MsrA}^{-{ }^{-}}$and $\mathrm{MsrA}^{+/+}$mice (Figure 6, A-C). These results suggested that the increased susceptibility of $\mathrm{Msr}^{-/-}$mice to cerebral ischemia/reperfusion injury is largely dependent on NF- $\mathrm{kB}$ activity. Consistent with this finding, more extensive infiltration of phopsho-p65positive cells into the infarcted brain regions was observed in $\mathrm{MsrA}^{-/-}$mice compared with $\mathrm{MsrA}^{+/+}$mice $(P<0.05)$, and this effect was completely prevented by the NBD peptide (Figure 6, D and E). Neutrophil infiltration also was greater in the infarcted cerebral regions of $\mathrm{MsrA}^{-/-}$mice compared with $\mathrm{MsrA}^{+/+}$mice $(P<0.01)$, and it was significantly blunted by the NBD peptide (Figure 6, F and $\mathrm{G}$ ). In agreement with our in vitro findings, prior administration of the CaMKII inhibitor $\mathrm{KN}-93\left(5 \mathrm{mg} / \mathrm{kg}\right.$ i.p.) also protected $\mathrm{Msr}^{-1-}$ mice from exacerbated infarct volumes and neurological deficits after cerebral ischemia/reperfusion injury (Figure 7). Together, these findings suggest that the increased susceptibility of $\mathrm{MsrA}^{-/-}$mice to cerebral ischemia/reperfusion injury is mediated in part by CaMKII-induced NF-kB activation and subsequent neutrophil infiltration, which is known to exacerbate neurovascular inflammation and cerebral tissue damage in ischemic stroke (31).

Protection from cerebral injury is mediated by MsrA in nonhematopoietic cells. Because NF-kB may contribute to cerebral inflammation by activating transcriptional pathways in both hematopoietic cells, such as neutrophils, and nonhematopoietic cells such as endothelial cells and glial cells, we performed bone marrow 
A
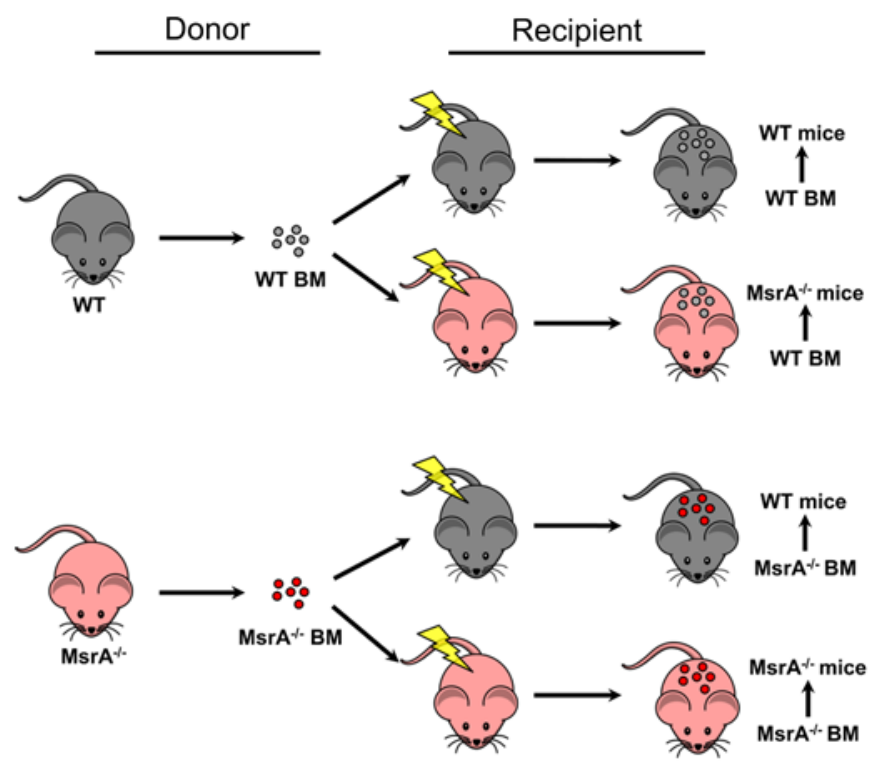

B

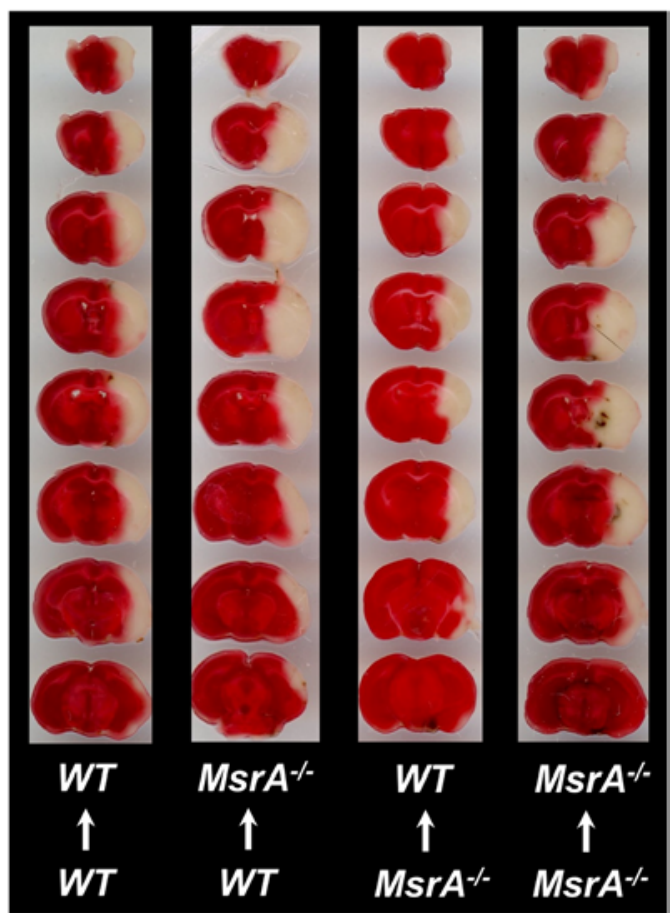

C

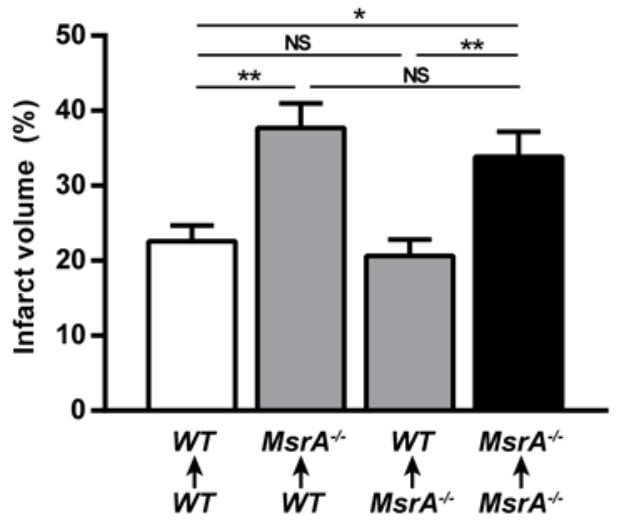

D

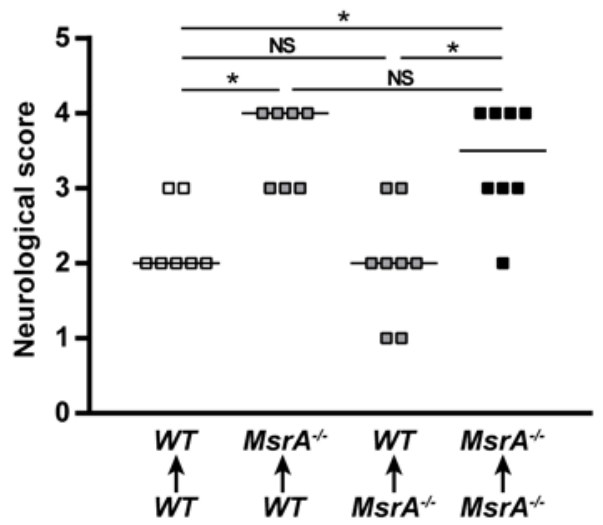

Figure 8. Protection from cerebral ischemia/reperfusion injury is mediated by MsrA in nonhematopoietic cells. (A) Schematic representation of bone marrow transplantation protocol. Bone marrow (BM) from $\mathrm{MsrA}^{+/+}$(WT) or MsrA ${ }^{-/-}$mice was transplanted into either WT or MsrA ${ }^{-/-}$recipient mice to generate 4 experimental groups of mice as indicated. (B) Representative 2,3,5-triphenyltetrazolium chloride-stained (TTC-stained) serial coronal sections of WT or $\mathrm{MsrA}^{-1-}$ mice transplanted with WT or $\mathrm{MsrA}^{-1-}$ bone marrow, 24 hours after tMCAO. Viable tissue was stained red, whereas infarcted area was unstained (white). (C) Corrected mean infarct volumes of each group expressed as mean $\pm \mathrm{SEM}\left(n=7-8\right.$ mice/group). ${ }^{*} P<0.05$; ${ }^{* *} P<0.01$, 2-way ANOVA with Tukey's multiple comparisons test. (D) Neurological score of each group expressed as scatter plots, with horizontal lines depicting the median. ${ }^{*} P<0.05$, ANOVA on ranks.

transplantation (BMT) experiments to generate chimeric mice deficient in MsrA selectively in either the hematopoietic or nonhematopoietic cell compartments (WT BM $\rightarrow M_{s r} A^{-/-}$mice; $M s r A^{-/-} \mathrm{BM} \rightarrow \mathrm{WT}$ mice) (Figure 8A). Control groups included $\mathrm{Msr}^{+/+}$and $\mathrm{Msr}^{\mathrm{A}^{-/}}$mice that were subjected to an identical BMT protocol (WT BM $\rightarrow$ WT mice; $M s r A^{-/-} \mathrm{BM} \rightarrow M s r A^{-/-}$mice). Transplantation efficiency was verified by genotyping peripheral blood cells 35 days after transplantation. Complete blood counts after BMT were similar in all groups (data not shown). As expected, $\mathrm{Msr}^{\mathrm{A}^{-/}} \mathrm{BM} \rightarrow \mathrm{Msr}^{-/-}$mice exhibited larger infarct volumes and more severe neurological deficits after tMCAO than WT BM $\rightarrow$ WT mice $(P<0.05)$ (Figure 8, B-D), a finding similar to that seen in mice that were not transplanted (Figure 5). In the chimeric mice, however, the phenotype after tMCAO was determined by the nonhematopoietic cell genotype rather than the bone marrow genotype. For example, $M s r A^{-/-} \mathrm{BM} \rightarrow \mathrm{WT}$ mice had similar infarct volumes and neurological outcomes compared with WT BM $\rightarrow$ WT mice. Similarly, WT BM $\rightarrow M s r A^{-/-}$mice had 
A
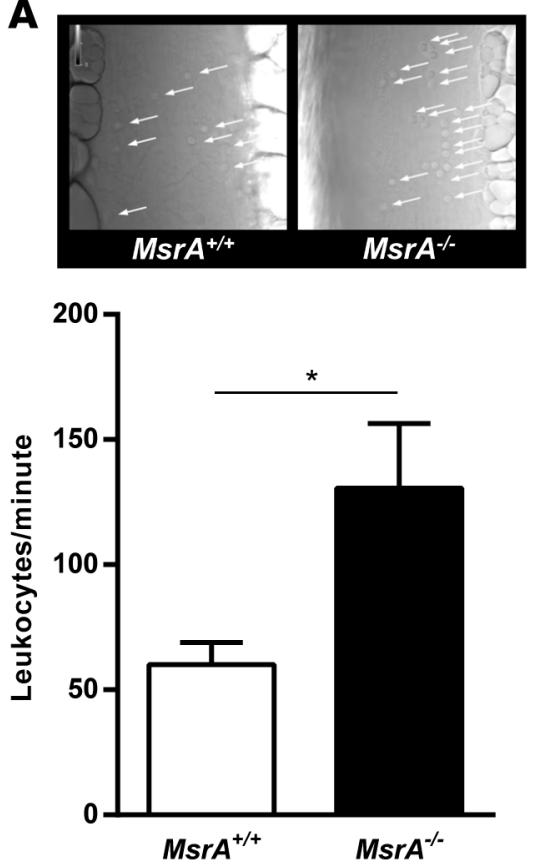

B
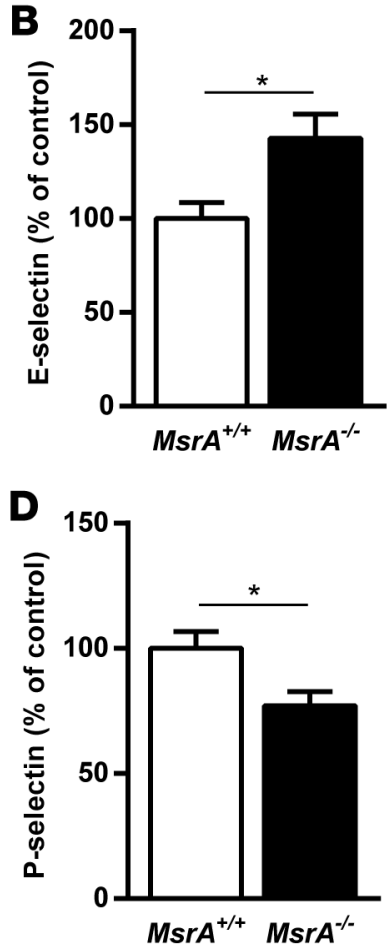

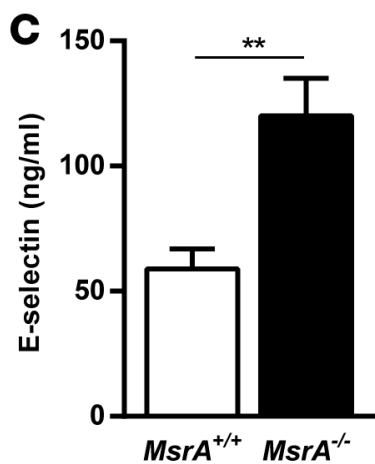

$\mathbf{E}$

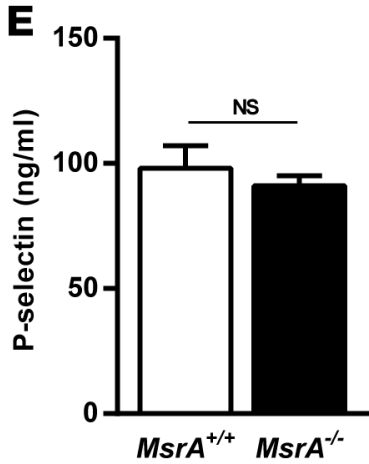

Figure 9. $\mathbf{M s r A}^{-/-}$mice exhibit increased leukocyte rolling. (A) Intravital microscopic images showing rolling leukocytes (arrows) in mesenteric postcapillary venules and quantification of the number of rolling leukocytes per minute between $\mathrm{Msr}^{+/+}$and $\mathrm{MsrA}^{-/-}$mice. Mean for each individual mouse was calculated from 2 to 3 venules per mouse. Data are represented as mean $\pm \operatorname{SEM}(n=5-6)$. Original magnification, $\times 40$. (B) E-selectin mRNA levels in lungs measured by RT-PCR and (C) soluble E-selectin protein levels measured by ELISA of blood from $\mathrm{MsrA}^{+/+}$and $M s r \mathrm{~A}^{-/-}$mice. (D) P-selectin mRNA levels in lungs measured by RT-PCR and (E) soluble P-selectin protein levels measured by ELISA of blood from MsrA ${ }^{+/+}$and $\mathrm{MsrA}^{-/-}$mice. Data are represented as mean $\pm \operatorname{SEM}(n=6) .{ }^{*} P<0.05 ;{ }^{* *} P<0.01,2$-sided, unpaired Student's $t$ test.

similar stroke outcomes as compared with $\mathrm{Msr}^{-1-} \mathrm{BM} \rightarrow M s r A^{-1-}$ mice. These findings demonstrate that $M s r A^{+/+}$bone marrow is unable to protect $M s r A^{-/-}$mice from increased susceptibility to cerebral ischemia/ reperfusion injury, suggesting that it is MsrA that protects from cerebral ischemia/reperfusion injury in nonhematopoietic cells.

$M s r A^{-1-}$ mice exhibit increased leukocyte rolling and upregulation of E-selectin. To further address the mechanism of increased neutrophil infiltration observed in the infarcted tissue of $M s r A^{-/-}$mice (Figure $6, \mathrm{~F}$ and G), we examined selectin-mediated leukocyte rolling on the endothelia of $M s r A^{+/+}$and $\mathrm{MsrA}^{-/-}$mice in vivo. The initial steps in neutrophil infiltration are mediated via interactions of circulating neutrophils with endothelial P- and E-selectin (32). Leukocyte rolling on mesenteric venules, as assessed by intravital microscopy, was significantly enhanced in $\mathrm{Msr}^{-/-}$mice compared with $M s r A^{+/+}$mice $(P<0.05)$ (Figure 9A and Supplemental Videos 1 and 2). Expression of E-selectin, an NF- $\mathrm{B}$-regulated gene $(33,34)$, was significantly elevated in $M s r A^{-/-}$mice compared with $M s r A^{+/+}$mice $(P<0.05)$ (Figure 9B), and plasma levels of soluble E-selectin were 2-fold higher in $\mathrm{Msr}^{-/-}$mice than in $M s r A^{+/+}$mice $(P<0.05)$ (Figure 9C). In contrast, expression of P-selectin mRNA was decreased in $M s r A^{-1-}$ mice (Figure 9D), and plasma levels of soluble P-selectin were not elevated in $M s r A^{-/-}$mice compared with $M s r A^{+/+}$mice (Figure 9E). These findings suggest that the increased leukocyte rolling observed in $M s r A^{-/-}$mice is mediated in part by increased endothelial expression of E-selectin, an NF- $\mathrm{BB}$-regulated adhesion molecule that has been shown previously to contribute to cerebrovascular inflammation and tissue injury in ischemic stroke (34-36).

\section{Discussion}

Our findings shed light on the mechanism of reperfusion injury in acute ischemic stroke. It is well recognized that ROS generated in response to ischemia/reperfusion can lead to dysregulated redox balance with adverse consequences on cellular function (37). After acute ischemic stroke, the generation of ROS when blood flow is reestablished to ischemic brain regions triggers an inflammatory response that compounds 


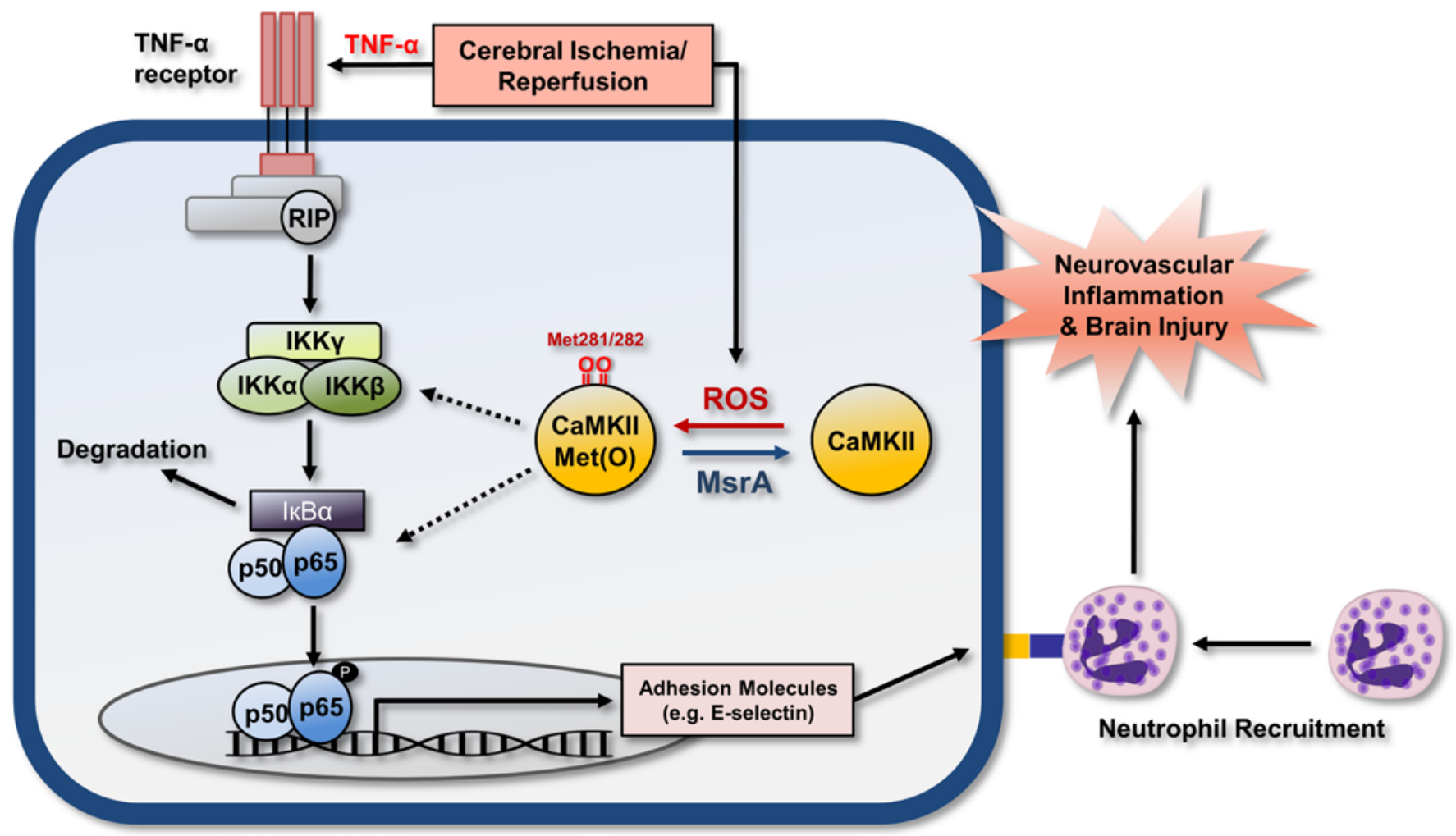

Figure 10. Schematic representation of a mechanistic pathway for neurovascular inflammation triggered by reperfusion injury. Cerebral ischemia/reperfusion induces generation of cytokines such as TNF- $\alpha$ that can activate NF-KB-dependent gene transcription and promote neurovascular inflammation through the classical pathway of NF-KB activation: (a) ligation of the TNF- $\alpha$ receptor leads to recruitment of receptor-interacting protein (RIP) kinases; (b) phosphorylation and activation of the IKK complex; (c) phosphorylation and degradation of $1 \kappa B \alpha$; and (d) phosphorylation of p65 and translocation of phospho-p65 into the nucleus. In parallel, reperfusion induces the generation ROS, leading to oxidation of CaMKII Met281/282 (red arrow), resulting in autonomous kinase activity. Oxidized CaMKII enhances NF-KB activation at several steps in the pathway (dashed arrows) and leads to enhanced neutrophil recruitment through transcriptional activation of adhesion molecules, such as E-selectin, which exacerbate neurovascular inflammation and brain injury. MsrA reverses CaMKII Met281/282 oxidation (blue arrow), dampens NF-KB-dependent neutrophil recruitment, and protects from cerebral ischemia/reperfusion injury.

tissue injury (4). Our results suggest that this postischemic ROS-driven inflammatory response is mediated by a pathway involving protein methionine oxidation and $\mathrm{NF}-\kappa \mathrm{B}$ activation (Figure 10). Specifically, we have found that (a) the NF- $\mathrm{BB}$ pathway is positively regulated by ROS via protein methionine oxidation in endothelial cells in vitro and in vivo, (b) the augmented activation of NF- $\mathrm{BB}$ by ROS is mediated in part through oxidation of CaMKII Met281/282, (c) MsrA plays a key role in protecting against NF- $\kappa \mathrm{B}$ activation and cerebral ischemia/reperfusion injury, (d) the protective effect of MsrA on cerebral ischemia/ reperfusion injury occurs through its expression in nonhematopoietic cells rather than in myeloid cells, and (e) the accentuated brain injury in $\mathrm{MsrA}^{-/-}$mice is prevented by inhibition of either NF- $\mathrm{KB}$ or CaMKII. These findings indicate that protein methionine oxidation is a potentially reversible mechanism mediating reperfusion injury in acute ischemic stroke.

The identification of protein methionine oxidation as a key mechanism of ROS-driven inflammation in postischemic brain injury is consistent with several previous observations. The hypothesis that ROS can exacerbate stroke severity after transient cerebral ischemia is based primarily on previous studies in which nonspecific antioxidant enzymes, such as superoxide dismutase or glutathione peroxidase, were found to be protective (5-8). We now have extended these prior observations by defining a protective role for MsrA, a more specific antioxidant enzyme that selectively reduces methionine sulfoxide residues within proteins (23). Many prior studies have suggested that ROS can regulate the NF-kB pathway $(11,12)$, but the overall effects of ROS on NF- $\mathrm{KB}$ activation appear to be complex and bidirectional (13). Our in vitro results in cultured endothelial cells clearly show that the net effect of ROS is to activate rather than repress NF- $\mathrm{B}$. The mammalian Msr system is composed of two groups of enzymes, MsrA and MsrB, which catalyze the stereospecific reduction of the $S$ and $R$ diastereomers of protein methionine sulfoxide, respectively (23). Our results demonstrate that ROS-induced NF- $\mathrm{kB}$ activation is prevented by MsrA, which implicates pro- 
tein methionine- $S$-sulfoxide as a potentiator of NF- $\kappa \mathrm{B}$ activation. A key protective role for MsrA also was demonstrated in vivo using the tMCAO model of cerebral ischemia/reperfusion, in which $M s r A^{-/-}$mice exhibited enhanced brain injury that could be prevented by inhibiting the NF- $\mathrm{kB}$ pathway. Interestingly, ROS-induced NF- $\mathrm{kB}$ activation in vitro was not prevented by MsrB1, which suggests that stereospecificity may be important in the redox regulation of the $\mathrm{NF}-\kappa \mathrm{B}$ pathway.

The role of NF- $\mathrm{KB}$ in ischemic stroke is highly dynamic. It is well established that cerebral ischemia/ reperfusion triggers an inflammatory response characterized by the generation of cytokines, such as TNF- $\alpha$ and IL-1, as well as Toll-like receptor ligands, many of which can activate the NF-kB pathway (38). The impact of NF- $\mathrm{kB}$ transcriptional activity on stroke outcomes appears to be temporally regulated by the timing of NF- $\mathrm{KB}$ activation during stroke progression $(10,39)$. Activation of NF- $\kappa \mathrm{B}$ in the early phase (within hours) of cerebral ischemia/reperfusion has been shown to exacerbate brain injury $(40,41)$. In contrast, some studies have suggested that NF- $\mathrm{KB}$ activation during later phases can paradoxically mitigate stroke injury through antiapoptotic mechanisms $(42,43)$. The tMCAO model of experimental stroke used in our studies mimics the acute phase of stroke progression when ROS generation during early reperfusion of the ischemic tissue likely plays a prominent role. Using this model, we found that mice with MsrA deficiency were more susceptible to cerebral ischemia/reperfusion injury and were protected by administration of a pharmacological NF- $\mathrm{kB}$ inhibitor prior to ischemia (Figure 5 and Figure 6). These findings are concordant with previous studies demonstrating an important role of MsrA in inflammation and $\mathrm{NF}-\mathrm{\kappa B}$ regulation in atherosclerosis (16) and ischemia/reperfusion injury in myocardium (18). Our observation that NF- $\mathrm{B}$ activation contributes to the increased susceptibility of $\mathrm{Msr}^{-/-}$mice to cerebral ischemia/reperfusion injury also is consistent with a recent report implicating MsrA in protection from NF- $\mathrm{kB}$ activation in rat microglia in a model of neuroinflammation induced by lipopolysaccharide (22).

Focal cerebral ischemia/reperfusion induces a time-dependent infiltration of circulating inflammatory cells, initially neutrophils and then macrophages and T cells (44). During the initial minutes to hours after onset of reperfusion, the endothelium becomes activated and transiently expresses adhesion molecules, facilitating the recruitment of neutrophils that exacerbate tissue damage through the release of proinflammatory mediators (31). Inhibition of neutrophil recruitment through the targeting of adhesion molecules such as E-selectin has been shown to reduce infarct size and improve neurological outcomes in experimental stroke (45). Interestingly, we observed significantly increased infiltration of neutrophils in the infarcts of $M s r A^{-/-}$mice compared with $\mathrm{Msr}^{+/+}$mice following tMCAO (Figure 6). Furthermore, we observed increased leukocyte rolling on endothelium and upregulation of E-selectin expression in $\mathrm{Msr}^{\mathrm{A}^{-/}}$mice (Figure 9). E-selectin is an NF- $\mathrm{BB}$-dependent adhesion molecule involved in neutrophil recruitment to vascular endothelium that has been implicated as a mediator of brain injury in ischemic stroke $(33,34)$. GWAS have identified a polymorphism in the human E-selectin locus that is associated with increased risk for stroke (36). In mice, E-selectin inhibition has been shown to mitigate postischemic cerebral injury after tMCAO $(35,46)$. Together with these previous observations, our results support a mechanistic pathway of ROSdriven postischemic cerebral inflammation mediated by protein methionine oxidation of CaMKII, leading to enhanced NF- $\mathrm{KB}$ activation and upregulated expression of E-selectin and other proinflammatory genes within the NF- $\kappa$ B transcriptome (Figure 10).

The NF-кB transcriptional pathway is active in multiple cell types, including bone marrow-derived myeloid cells as well as nonhematopoietic cells that may contribute to neurovascular inflammation in ischemic stroke $(44,47)$. To determine whether the protective effect of MsrA on ischemia/reperfusion injury is mediated by myeloid cells such as neutrophils, we used a BMT approach. We found that the exacerbated tMCAO phenotype of $M s r A^{-/-}$mice was clearly determined by the $M s r A$ genotype of the irradiated recipient rather than the $M s r A$ genotype of the nonirradiated bone marrow donor (Figure 8). These findings suggest that it is deficiency of MsrA in cells of nonhematopoietic origin (vascular endothelium and possibly other resident CNS cells such as microglia, ref. 22, or neurons, ref. 48) that protects from reperfusion injury. Additional work using tissue-specific approaches will be required to further define the specific role of neurovascular endothelial cells versus other nonhematopoietic cell types.

Our findings using the CaMKII inhibitor KN-93 suggest a mechanistic role for CaMKII in mediating ROS-driven NF- $\mathrm{KB}$ activation in vitro and cerebral ischemia/reperfusion injury in vivo. These observations are consistent with previous work showing that CaMKII can promote $\mathrm{NF}-\kappa \mathrm{B}$ activation in gastric cancer (49), small-cell lung cancer (50), lymphoblastoid cells (51), and gastric epithelial cells (52). CaMKII also has been shown to contribute to NF-kB-dependent myocardial hypertrophy, myocardial ischemia/reper- 
fusion injury, and mortality following myocardial infarction in animal models $(25,27)$. CaMKII has been proposed to act at several different steps in the canonical NF- $\kappa \mathrm{B}$ signaling pathway by directly phosphorylating p65 and other p65 kinases and by enhancing the phosphorylation and proteosomal degradation of I $\mathrm{B}$ through phosphorylation of IKK $\beta$ (53). The regulatory domain of CaMKII contains two redox-active methionine residues (Met281/282) that when oxidized enhance CaMKII activation, resulting in autonomous kinase activity (24). Oxidation of CaMKII Met281/282 increases infarct size and mortality after myocardial infarction $(24,54,55)$ and can contribute to cardiac arrhythmias (56-59). $M s r A^{-/-}$mice have increased angiotensin II-induced CaMKII oxidation and are more susceptible to myocardial infarction (24), whereas transgenic mice that overexpress MsrA are less susceptible to CaMKII oxidation, atrial fibrillation, and myocardial infarction (54, 57). Mice expressing an oxidation-resistant CaMKII (M281/282V) were found to be protected from diabetes-attributable mortality after myocardial infarction (55). In the vasculature, CaMKII Met281/282 oxidation occurs in conditions of increased oxidative stress and promotes smooth muscle migration and apoptosis $(60,61)$. Importantly, CaMKII Met281/282 oxidation has been shown to be involved in regulation of the NF- $\mathrm{KB}$ pathway and inflammatory mechanisms associated with cardiac hypertrophy and asthma $(26,62)$.

Our findings support and extend these previous observations and provide a potential mechanistic explanation for the pathological role of protein methionine oxidation in cerebral reperfusion injury. We found that $\mathrm{H}_{2} \mathrm{O}_{2}$ enhanced NF- $\mathrm{\kappa B}$ activation and increased CaMKII Met281/282 oxidation in endothelial cells, both of which were reversed by overexpression of MsrA (Figure 2 and Figure 3). $\mathrm{H}_{2} \mathrm{O}_{2}$-augmented $\mathrm{NF}-\kappa \mathrm{B}$ activation also was eliminated with an oxidation-resistant CaMKII methionine mutant (CaMKII M281/282V). Furthermore, the pharmacological CaMKII inhibitor $\mathrm{KN}$-93 decreased $\mathrm{H}_{2} \mathrm{O}_{2}$-augmented $\mathrm{NF}-\kappa \mathrm{B}$ activation in vitro and protected $\mathrm{Ms}_{\mathrm{A}} \mathrm{A}^{-/-}$mice from cerebral ischemia/reperfusion injury (Figure $3 \mathrm{~A}$ and Figure 7). KN-93 is a competitive inhibitor that prevents $\mathrm{Ca}^{2+} /$ calmodulin from displacing the regulatory domain from the catalytic domain and thus blocks the transient calcium-dependent CaMKII activation that is required for autonomous CaMKII activity induced by phosphorylation or protein methionine oxidation (14). KN-93 is relatively selective for CaMKII, but it also inhibits CaMKI, CamKIV, and some other protein kinases and ion channels (63). Taken together, these studies suggest that methionine oxidation of CaMKII may contribute to NF- $\mathrm{CB}$-dependent reperfusion injury, but future experiments will require the use of more specific inhibitors of CaMKII, as well as genetic approaches to CaMKII inhibition, to further define the role of CaMKII.

In summary, the results presented herein demonstrate that MsrA plays an important protective role in cerebrovascular inflammation and cerebral ischemia/reperfusion injury. MsrA exerts its protective effects through a mechanism involving redox regulation of the NF- $\mathrm{BB}$ pathway, which is likely mediated in part by reducing the protein methionine oxidation of CaMKII. These findings suggest that protein methionine oxidation is a key pathological mechanism of reperfusion injury during acute ischemic stroke. Potential therapeutic approaches to target this pathway may include MsrA mimetics $(16,22)$, CaMKII inhibitors (64), and NF- $\mathrm{KB}$ pathway modulators.

\section{Methods}

Mice. All animal use was carried out in accordance with the recommendations in the Guide for the Care and Use of Laboratory Animals of the NIH (National Academies Press. 2011). Male $M s r A^{-/-}$mice and WT $\left(M s r A^{+/+}\right)$ mice (C57BL/6J background) at 8 to 10 weeks of age were used for most studies (65). For studies of NF- $\kappa B$ activation, transgenic mice carrying a transgene with 3 binding sites for NF-кB (5'-GGGACTTTCC-3') coupled to the luciferase gene (referred to as $H L L$ mice) (C57BL/6J background, The Jackson Laboratory; ref. 28) were crossbred with $M s r A^{-/-}$mice to generate heterozygous $H L L$ mice that were either $M s r A^{+/+}$ or $\mathrm{MsrA}^{-/-}$. Genotyping was done by PCR using MsrA reverse (TCACACCCATCTGAGACTTCCCC), MsrA forward (ACGCTTCTTCATTCAGCTAAC), Neo left (GTGTTCCGGCTGTCAGCGCA), and Neo right (GTCGTGATAGCGGTCCGCCA) primers.

$t M C A O$. Focal cerebral ischemia was induced by transiently occluding the right middle cerebral artery based on modification of a previous protocol (66). Male mice weighing 22-25 g were anesthetized with a ketamine/xylazine mixture $(87.5 \mathrm{mg} / \mathrm{kg} / 12.5 \mathrm{mg} / \mathrm{kg}$ i.p.). An incision was made in the external carotid artery, and a 0.22-mm diameter silicon-covered 6-0 nylon monofilament (Doccol) was advanced 9-10 mm through the internal carotid artery to the proximal middle cerebral artery. Occlusion of the middle cerebral artery was documented by a decrease in laser Doppler signal to less than $20 \%$ of baseline values, after 
which the monofilament was secured in place. Following 60 minutes of ischemia, the monofilament was then removed to allow for reperfusion. After 24 hours of reperfusion, mice were evaluated for neurological deficits using a motor deficit scale (see below) and sacrificed for brain histology. For NF- $\mathrm{kB}$ inhibition experiments, mice were injected with $2 \mathrm{mg} / \mathrm{kg}$ NBD peptide (Enzo) or inactive analog (control peptide) i.p. 4 hours prior to tMCAO. For CaMKII inhibition experiments, $5 \mathrm{mg} / \mathrm{kg} \mathrm{KN}-93$ (Sigma-Aldrich) or inactive analog KN-92 was administered i.p. 4 hours prior to tMCAO. The dose of KN-93 was based on a previous report of i.p. administration in vivo (67).

Neurological scoring. Twenty-four hours after tMCAO, mice were evaluated for motor deficits using a 5-point scale: 0 , no observable neurological deficit (normal); 1 , failure to extend left forepaw when picked up by tail (mild); 2, mild circling to the contralateral side but normal posture at rest (moderate); 3 , consistent strong and immediate circling, falling to the contralateral side at rest (moderate to severe); 4 , severe postural rotation at rest progressing into barreling and loss of righting reflex (severe); and 5 , comatose or moribund.

Measurement of infarct volume. Twenty-four hours after tMCAO, cerebral infarct size was determined by 2,3,5-triphenyltetrazolium chloride (TTC) staining. Brains were cut from the frontal pole into 1-mm-thick serial coronal sections using a mouse Brain Matrix (Roboz Surgical Instrument). Sections were stained with $1 \%$ TTC at $37^{\circ} \mathrm{C}$ for 15 minutes and then fixed in $10 \%$ neutral-buffered formalin. Sections were scanned and infarct area was analyzed using NIH ImageJ software. To correct for brain swelling due to edema after ischemia the corrected total infarct volume (\%) was calculated as described (68): corrected infarct volume $(\%)=($ volume of contralateral hemisphere $-[$ volume of ipsilateral hemisphere - volume of infarct $]) /$ volume of contralateral hemisphere $\times 100$.

Immunohistochemical staining. Immunohistochemical staining for neutrophils and phospho-p65 was performed on brain sections after tMCAO. Slides were incubated with blocking reagent followed by primary antibody (rat anti-mouse Ly6B.2 specific for neutrophils [Abd Serotec] and phospho-NF-кB p65 [Ser536] [Cell Signaling]) or respective Ig controls overnight at $4^{\circ} \mathrm{C}$. The next day, slides were rinsed and stained with biotin-conjugated rabbit anti-rat Ig or goat anti-rabbit Ig, avidin-linked enzyme peroxidase complex, and 3, 3'-diaminobenzidine as substrate. Slides were counterstained with hematoxylin, dehydrated, and examined under a light microscope (Zeiss). For quantification, immunoreactive cells (brown staining) were counted in different cerebral regions of the infarct at $\times 20$ and $\times 40$ magnification. Each mouse represents a mean of 16 fields from 4 serial coronal sections (separated by $100 \mu \mathrm{m}$ ). The number immunoreactive cells was expressed as the number of immunoreactive cells per square millimeter of the infarct region. NIH ImageJ was used for quantification.

$B M T$. BMT was performed in $M s r A^{+/+}$and $M s r A^{-/-}$mice as described previously (68). Bone marrow cells were collected from the femurs and tibias of 6- to 7-week-old donor mice using Ficoll gradient centrifugation. Recipient mice were irradiated with 2 fractions of $6.5 \mathrm{~Gy}$, with an interval of 4 hours between the first and second irradiations. Bone marrow cells $\left(1 \times 10^{7}\right)$ were resuspended in sterile PBS and injected into the retro-orbital venous plexus of lethally irradiated recipient mice. After transplantation, mice were maintained in sterile cages and fed autoclaved food and water ad libitum. BMT success was analyzed after 4 weeks by PCR to check presence of the genomic DNA (of the respective donor mice) in peripheral blood mononuclear cells from transplanted mice. Complete blood counts were obtained using an ADVIA 120 automated hematology analyzer (Siemens) to ascertain that BMT did not affect the number of bone marrow-derived blood cells.

Cell culture and adenoviruses. HUVECs were obtained from Lonza Corporation and cultured in EGM2 growth medium. Cells were used between passages 2 and 10 . All cells were maintained at $37^{\circ} \mathrm{C}$ in a $5 \% \mathrm{CO}_{2}$ incubator. Ad-NF-кBLuc, Ad-CaMKII, and Ad-CaMKII-M281/282V were obtained from the University of Iowa Viral Vector Core Facility $(61,62,69)$. Adenoviruses encoding Myc-tagged MsrA or FLAG-tagged MsrB1 were generated by homologous recombination with assistance from the University of Iowa Vector Core Facility. HUVECs were grown to $80 \%$ to $90 \%$ confluency and infected with adenoviruses in serum-free medium at the following MOI: Ad-NF-кBLuc (MOI = 1,000), Ad-CaMKII $(\mathrm{MOI}=1,000)$, Ad-CaMKII-M281/282V (MOI = 1,000), Ad-MsrA (MOI = 100), Ad-MsrB1 (MOI = 500), and Ad-Cre $(\mathrm{MOI}=100)$. After 6-hour incubation at $37^{\circ} \mathrm{C}$, the adenovirus was washed off and replaced with complete growth medium. To analyze the efficiency of transduction, GFP expression was monitored each day by fluorescence microscopy (Olympus IX-81). At 40 hours after infection, cells were treated with different reagents then lysed for luciferase assay and immunoblot analysis. 
Luciferase assay. The Luciferase Assay System with Reporter Lysis Buffer (Promega) was used to measure $\mathrm{NF}-\kappa \mathrm{B}-$ mediated transcriptional induction according to the manufacturer's protocol. The NF- $\mathrm{BB}-\mathrm{respon}-$ sive luciferase reporter, Ad-NF-kBLuc, was used to coinfect cells at a MOI of 1,000 particles/cell in cell culture experiments. For the luciferase experiments with $H L L$ mice, tissues were homogenized in PBS and then lysed using reporter lysis buffer. Luciferin was added to the lysate, and luciferase activity was read in a 96-well MicroLumatPlus luminometer (Berthold Technologies) according to the manufacturer's protocol. All measurements of luciferase activity (relative light units) were normalized to the protein concentration.

Immunoblotting. Cells or tissues were lysed in RIPA buffer (25 mM Tris, $\mathrm{pH} 7.4,150 \mathrm{mM} \mathrm{NaCl}, 0.1 \%$ Triton $\mathrm{X}-100$ ) containing $0.1 \%$ SDS and protease inhibitors (Roche). Total protein concentration was determined by Bradford assay (Bio-Rad). Lysates were treated with sample loading buffer, and $\sim 25 \mu$ g were loaded onto a $10 \%$ SDS-polyacrylamide gel. After electrophoresis, gels were transferred to a nitrocellulose membrane. Membranes were blocked for 1 hour in blocking buffer (5\% nonfat dry milk, $100 \mathrm{mM}$ Tris-HCl, pH 7.4, 0.1\% Tween-20). Membranes were incubated with the following primary antibodies overnight at $4^{\circ} \mathrm{C}$ : anti-c-Myc $(1: 5,000$, SigmaAldrich M4439), anti-FLAG M2 (1:2,000, Sigma-Aldrich F3165), anti- $\beta$-Actin (1:5,000, Abcam ab8227), anti-

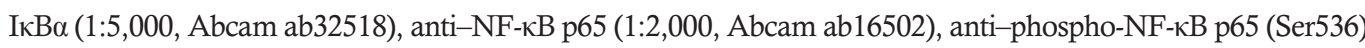
(1:1,000, Cell Signaling 3033), anti-CaMKII (1:2,000, Abcam ab52476), anti-phospho-CaMKII (Thr286) (1:2,000, Cell Signaling 3361), anti-ox-CaMKII (Met281/282) (1:500, from Mark Anderson, University of Iowa Carver College of Medicine; ref. 24), or anti-fibrin/fibrinogen (1:4,000, Acris AP00766PU-N). Membranes were then incubated with respective secondary antibodies conjugated to horseradish peroxidase (Thermo Scientific). Antibody-bound protein bands were then visualized using a horseradish peroxidase-dependent chemiluminescence Femto kit (Thermo Scientific). Quantification was performed by densitometry using NIH ImageJ.

Immunofluorescence. Aortas and carotid arteries from HLL mice were isolated and frozen in OCT medium. Tissues were cryosectioned (Leica Microm Cryostat) into $10-\mu \mathrm{M}$-thick sections and mounted on glass slides. Slides were fixed with $10 \% \mathrm{Zn} /$ formalin solution and blocked for 1 hour in blocking buffer ( $1 \times$ PBS, $5 \%$ normal goat serum, 10\% BSA). Sections were incubated with anti-luciferase (1:1,000, Abcam ab21176) and/or anti-CD31 (1:500, Abcam ab56299) overnight at $4^{\circ} \mathrm{C}$ followed by 1-hour incubation with goat anti-rabbit Alexa Fluor 488 or goat anti-rat Alexa Fluor 568 secondary antibodies (Thermo Scientific), respectively. Sections were mounted with medium containing DAPI (VectaShield). Images were taken by fluorescence microscopy at $\times 40$ or $\times 60$ magnification (Olympus BX-61). All images were taken at the same time and using the same imaging settings.

Isolation of microvascular endothelial cells. Mice were euthanized with $\mathrm{CO}_{2}$, and organs were perfused with PBS by intracardiac perfusion. Brains were excised and pooled ( 3 brains per group) to maximize yield (approximately $1 \%-2 \%$ of the cells of brain tissue are endothelial cells). Mouse BMVECs were obtained from whole brain using a protocol published previously (70). Briefly, whole brain was mechanically minced using surgical blades. Tissue was enzymatically digested with collagenase II (Invitrogen), dispase (Invitrogen), and DNAse (Sigma-Aldrich) and then filtered using a $100-\mu \mathrm{m}$ cell strainer (BD Biosciences) to create a single-cell suspension. Endothelial cells were isolated from the single-cell suspension by fluorescence-activated cell sorting using PE-labeled rat anti-mouse CD31 (1:100, Pharmagen 553373) with technical assistance from the University of Iowa Flow Cytometry Facility.

Real-time PCR. Total RNA was isolated from lung using a RNA isolation kit (Ambion), and contaminating genomic DNA was removed by DNA-free Kit (Ambion). RNA ( 400 ng per sample) was then reverse transcribed using iScript Reverse Transcription Supermix for RT-PCR (Bio-Rad) to obtain cDNA. Reaction was run on Veriti 96 Well Thermal Cycler; cycling conditions were $25^{\circ} \mathrm{C}$ for 5 minutes, $42^{\circ} \mathrm{C}$ for 30 minutes, and $85^{\circ} \mathrm{C}$ for 5 minutes. PCR primers and 6-carboxy fluorescein-labeled probes for GAPDH (Mm99999915 g1), P-selectin (Mm01204601_m1), and E-selectin (Mm00441278_m1) were purchased from Thermo Scientific. RT-PCR reactions were run on Applied Biosystems 7900HT Fast Real-Time PCR machine in University of Iowa Genomics Division. Cycling conditions were $50^{\circ} \mathrm{C}$ for 2 minutes, $95^{\circ} \mathrm{C}$ for 10 minutes, and 40 cycles of $95^{\circ} \mathrm{C}$ for 15 seconds and $60^{\circ} \mathrm{C}$ for 1 minute. Data were analyzed using the comparative threshold cycle $(\triangle \Delta \mathrm{CT})$ method with values normalized to GAPDH and expressed relative to levels in $\mathrm{Msr}^{+/+}$mice.

E-selectin ELISA. Blood was drawn by intracardiac puncture in a 1:9 ratio of acid citrate dextrose to whole blood. Plasma was isolated by centrifugation for 20 minutes at $1,000 \mathrm{~g}$ at $4^{\circ} \mathrm{C}$. Levels of serum soluble P-selectin (Mouse sP-Selectin/CD62P Quantikine ELISA, R\&D Systems) and E-selectin (Mouse E-Selectin/CD62E Quantikine ELISA, R\&D Systems) were measured with monoclonal antibody-based ELISA kits according to the manufacturer's guidelines. 
Leukocyte rolling. Mice were anesthetized with $2.5 \%$ tribromoethanol $(0.15 \mathrm{ml} / 10 \mathrm{~g})$, and a midline incision was made through the abdominal wall to expose mesentery and mesenteric veins of 200 to $300 \mu \mathrm{m}$ diameter. The exposed mesentery was kept moist throughout the experiment by periodic superfusion of prewarmed $\left(37^{\circ} \mathrm{C}\right)$ saline. The mesentery was transilluminated with a $12 \mathrm{~V}, 100 \mathrm{~W}, \mathrm{DC}$-stabilized source. Veins were visualized using a Nikon inverted microscope connected to a high-speed electron magnifying camera. Leukocyte interaction with the endothelium vessel wall at baseline was recorded in phase contrast for 10 minutes each in 2 to 3 veins per mouse. Recorded images for leukocyte rolling were analyzed manually by counting the number of leukocytes passing through a plane perpendicular to the vessel axis during a 1-minute interval. Leukocyte rolling/minute/vein for each mouse was determined by taking the average of five 1-minute counts.

Carotid artery thrombosis. Carotid artery thrombosis was induced by direct chemical injury with ferric chloride $\left(\mathrm{FeCl}_{3}\right)$ as described previously (71). Mice were anesthetized with sodium pentobarbital (70 to $90 \mathrm{mg} / \mathrm{kg}$ i.p.) and ventilated mechanically with room air and supplemental oxygen using a Harvard rodent respirator. The right common carotid artery was dissected free, and carotid artery blood flow was measured with a 0.5 PSB Doppler flow probe (Transonic Systems Inc.) and a digital recording system (Gould Ponemah Physiology Platform Version 3.33). To induce chemical injury, a $1 \mathrm{~mm} \times 1 \mathrm{~mm}$ Whatman No. 1 filter paper saturated in $7 \% \mathrm{FeCl}_{3}$ was applied to the adventitial surface of the right common carotid artery for 3 minutes. The filter paper was then removed, and the tissue was rinsed with warm saline. Blood flow was monitored continuously for 30 minutes or until stable occlusion occurred, at which time the experiment was terminated.

IVC thrombosis. Susceptibility to thrombosis in the venous system was measured as described previously (72). Briefly, mice were anesthetized with ketamine/xylazine $(87.5 \mathrm{mg} / \mathrm{kg}$ ketamine and $12.5 \mathrm{mg} / \mathrm{kg}$ xylazine i.p.). A midline laparotomy was made, and the IVC was exposed directly via blunt dissection. The IVC was ligated inferiorly to the left renal vein with a 6-0 silk suture, and mice were allowed to recover. Two days later, the IVC was harvested for measurement of the length and weight of thrombus.

Statistics. Statistical analysis was performed using 2-tailed Student's $t$ test, 1-way ANOVA, or 2-way ANOVA with Tukey's test. Nonparametric data were analyzed by the Mann-Whitney $U$ test or ANOVA on ranks. Data are expressed as mean \pm SEM unless otherwise stated. $P<0.05$ was considered to be statistically significant.

Study approval. The animal protocol was approved by the Institutional Animal Care and Use Committee of the University of Iowa, Iowa City.

\section{Author contributions}

SXG designed the research, conducted experiments, acquired data, analyzed data, and wrote the manuscript. IOB conducted experiments, analyzed data, and revised the manuscript. KMW conducted experiments, acquired data, analyzed data, and revised the manuscript. ND conducted experiments, analyzed data, and revised the manuscript. PD conducted experiments, analyzed data, and revised the manuscript. IMG provided reagents and expertise and revised the manuscript. AKC conducted experiments, analyzed data, and revised the manuscript. SRL designed the research, analyzed data, and revised the manuscript.

\section{Acknowledgments}

The authors thank Jeff Stevens for scientific inspiration and technical advice, and Prem Prakash for assistance with the bone marrow transplantation protocol. This work was supported by NIH grants HL062984 to S.R. Lentz, HL118246 and HL118742 to A.K. Chauhan, HL108932 to I.M. Grumbach, and GM007337 to the University of Iowa Medical Scientist Training Program; a grant from the American Society of Hematology to S.R. Lentz; VA Office of Research and Development grant 1BX000163-01 to I.M. Grumbach; American Heart Association award 16IRG27490003 to A.K. Chauhan; and American Heart Association predoctoral awards to S.X. Gu and I.O. Blokhin.

Address correspondence to: Steven R. Lentz, Department of Internal Medicine, C21 GH, The University of Iowa, 200 Hawkins Drive, Iowa City, Iowa 52242, USA. Phone: 319.356.4048; Fax: 319.353.8383; E-mail: steven-lentz@uiowa.edu.

\footnotetext{
1. Mozaffarian D, et al. Heart disease and stroke statistics--2015 update: a report from the American Heart Association. Circulation. 2015;131(4):e29-322.

2. Tissue plasminogen activator for acute ischemic stroke. The National Institute of Neurological Disorders and Stroke rt-PA Stroke Study Group. N Engl J Med. 1995;333(24):1581-1587.
} 
3. Kalogeris T, Baines CP, Krenz M, Korthuis RJ. Cell biology of ischemia/reperfusion injury. Int Rev Cell Mol Biol. 2012;298:229317.

4. Olmez I, Ozyurt H. Reactive oxygen species and ischemic cerebrovascular disease. Neurochem Int. 2012;60(2):208-212.

5. Kinouchi H, Epstein CJ, Mizui T, Carlson E, Chen SF, Chan PH. Attenuation of focal cerebral ischemic injury in transgenic mice overexpressing CuZn superoxide dismutase. Proc Natl Acad Sci U S A. 1991;88(24):11158-11162.

6. Kondo T, et al. Reduction of CuZn-superoxide dismutase activity exacerbates neuronal cell injury and edema formation after transient focal cerebral ischemia. J Neurosci. 1997;17(11):4180-4189.

7. Crack PJ, et al. Increased infarct size and exacerbated apoptosis in the glutathione peroxidase-1 (Gpx-1) knockout mouse brain in response to ischemia/reperfusion injury. J Neurochem. 2001;78(6):1389-1399.

8. Crack PJ, Taylor JM, Ali U, Mansell A, Hertzog PJ. Potential contribution of NF-kappaB in neuronal cell death in the glutathione peroxidase-1 knockout mouse in response to ischemia-reperfusion injury. Stroke. 2006;37(6):1533-1538

9. Brigelius-Flohe R, Flohe L. Basic principles and emerging concepts in the redox control of transcription factors. Antioxid Redox Signal. 2011;15(8):2335-2381.

10. Harari OA, Liao JK. NF-kappaB and innate immunity in ischemic stroke. Ann N Y Acad Sci. 2010;1207:32-40.

11. Oliveira-Marques V, Marinho HS, Cyrne L, Antunes F. Role of hydrogen peroxide in NF-kappaB activation: from inducer to modulator. Antioxid Redox Signal. 2009;11(9):2223-2243.

12. Pantano C, Reynaert NL, van der Vliet A, Janssen-Heininger YM. Redox-sensitive kinases of the nuclear factor-kappaB signaling pathway. Antioxid Redox Signal. 2006;8(9-10):1791-1806.

13. Morgan MJ, Liu ZG. Crosstalk of reactive oxygen species and NF-kappaB signaling. Cell Res. 2011;21(1):103-115.

14. Gu SX, Stevens JW, Lentz SR. Regulation of thrombosis and vascular function by protein methionine oxidation. Blood. 2015;125(25):3851-3859.

15. Xu YY, et al. Hepatic overexpression of methionine sulfoxide reductase A reduces atherosclerosis in apolipoprotein E-deficient mice. J Lipid Res. 2015;56(10):1891-1900.

16. Wu Y, et al. PEP-1-MsrA ameliorates inflammation and reduces atherosclerosis in apolipoprotein E deficient mice. $J$ Transl Med. 2015;13(1):316.

17. Klutho PJ, et al. Deletion of methionine sulfoxide reductase A does not affect atherothrombosis but promotes neointimal hyperplasia and extracellular signal-regulated kinase 1/2 signaling. Arterioscler Thromb Vasc Biol. 2015;35(12):2594-2604.

18. Zhao H, et al. Myristoylated methionine sulfoxide reductase A protects the heart from ischemia-reperfusion injury. Am JPhysiol Heart Circ Physiol. 2011;301(4):H1513-1518.

19. Kim JI, Choi SH, Jung KJ, Lee E, Kim HY, Park KM. Protective role of methionine sulfoxide reductase A against ischemia/ reperfusion injury in mouse kidney and its involvement in the regulation of trans-sulfuration pathway. Antioxid Redox Signal. 2013;18(17):2241-2250.

20. Garcia-Bermudez M, et al. Association of the methionine sulfoxide reductase A rs10903323 gene polymorphism with cardiovascular disease in patients with rheumatoid arthritis. Scand J Rheumatol. 2012;41(5):350-353.

21. Gu H, Chen W, Yin J, Chen S, Zhang J, Gong J. Methionine sulfoxide reductase A rs10903323 G/A polymorphism is associated with increased risk of coronary artery disease in a Chinese population. Clin Biochem. 2013;46(16-17):1668-1672.

22. Fan H, et al. Methionine sulfoxide reductase A negatively controls microglia-mediated neuroinflammation via inhibiting ROS/ MAPKs/NF-kappaB signaling pathways through a catalytic antioxidant function. Antioxid Redox Signal. 2015;22(10):832-847.

23. Lee BC, Dikiy A, Kim HY, Gladyshev VN. Functions and evolution of selenoprotein methionine sulfoxide reductases. Biochim Biophys Acta. 2009;1790(11):1471-1477.

24. Erickson JR, et al. A dynamic pathway for calcium-independent activation of CaMKII by methionine oxidation. Cell. 2008;133(3):462-474.

25. Ling $\mathrm{H}$, et al. Ca2+/Calmodulin-dependent protein kinase II delta mediates myocardial ischemia/reperfusion injury through nuclear factor-kappaB. Circ Res. 2013;112(6):935-944

26. Singh MV, Swaminathan PD, Luczak ED, Kutschke W, Weiss RM, Anderson ME. MyD88 mediated inflammatory signaling leads to CaMKII oxidation, cardiac hypertrophy and death after myocardial infarction. J Mol Cell Cardiol. 2012;52(5):11351144 .

27. Singh MV, et al. Ca2+/calmodulin-dependent kinase II triggers cell membrane injury by inducing complement factor B gene expression in the mouse heart. J Clin Invest. 2009;119(4):986-996.

28. Blackwell TS, et al. Multiorgan nuclear factor kappa B activation in a transgenic mouse model of systemic inflammation. Am $J$ Respir Crit Care Med. 2000;162(3 Pt 1):1095-1101.

29. Stoll G, Kleinschnitz C, Nieswandt B. Molecular mechanisms of thrombus formation in ischemic stroke: novel insights and targets for treatment. Blood. 2008;112(9):3555-3562.

30. May MJ, D'Acquisto F, Madge LA, Glockner J, Pober JS, Ghosh S. Selective inhibition of NF-kappaB activation by a peptide that blocks the interaction of NEMO with the IkappaB kinase complex. Science. 2000;289(5484):1550-1554.

31. Jickling GC, Liu D, Ander BP, Stamova B, Zhan X, Sharp FR. Targeting neutrophils in ischemic stroke: translational insights from experimental studies. J Cereb Blood Flow Metab. 2015;35(6):888-901.

32. Ley K, Laudanna C, Cybulsky MI, Nourshargh S. Getting to the site of inflammation: the leukocyte adhesion cascade updated. Nat Rev Immunol. 2007;7(9):678-689.

33. Rahman A, Kefer J, Bando M, Niles WD, Malik AB. E-selectin expression in human endothelial cells by TNF-alpha-induced oxidant generation and NF-kappaB activation. Am J Physiol. 1998;275(3 Pt 1):L533-544.

34. Schindler U, Baichwal VR. Three NF-kappa B binding sites in the human E-selectin gene required for maximal tumor necrosis factor alpha-induced expression. Mol Cell Biol. 1994;14(9):5820-5831.

35. Huang J, et al. Postischemic cerebrovascular E-selectin expression mediates tissue injury in murine stroke. Stroke. 2000;31(12):3047-3053

36. Roy S, et al. Association of E-selectin gene polymorphism (S128R) with ischemic stroke and stroke subtypes. Inflammation. 2014;37(2):599-603.

37. Alfadda AA, Sallam RM. Reactive oxygen species in health and disease. J Biomed Biotechnol. 2012;2012:936486. 
38. Lambertsen KL, Biber K, Finsen B. Inflammatory cytokines in experimental and human stroke. J Cereb Blood Flow Metab. 2012;32(9):1677-1698.

39. Kriz J. Inflammation in ischemic brain injury: timing is important. Crit Rev Neurobiol. 2006;18(1-2):145-157.

40. Schneider A, Martin-Villalba A, Weih F, Vogel J, Wirth T, Schwaninger M. NF-kappaB is activated and promotes cell death in focal cerebral ischemia. Nat Med. 1999;5(5):554-559.

41. Desai A, Singh N, Raghubir R. Neuroprotective potential of the NF-kappaB inhibitor peptide IKK-NBD in cerebral ischemia-reperfusion injury. Neurochem Int. 2010;57(8):876-883.

42. Duckworth EA, Butler T, Collier L, Collier S, Pennypacker KR. NF-kappaB protects neurons from ischemic injury after middle cerebral artery occlusion in mice. Brain Res. 2006;1088(1):167-175.

43. Nijboer CH, Heijnen CJ, Groenendaal F, May MJ, van Bel F, Kavelaars A. Strong neuroprotection by inhibition of NF-kappaB after neonatal hypoxia-ischemia involves apoptotic mechanisms but is independent of cytokines. Stroke. 2008;39(7):2129-2137.

44. Iadecola C, Anrather J. The immunology of stroke: from mechanisms to translation. Nat Med. 2011;17(7):796-808.

45. Jin R, Yang G, Li G. Inflammatory mechanisms in ischemic stroke: role of inflammatory cells. J Leukoc Biol. 2010;87(5):779789.

46. Mocco J, et al. HuEP5C7 as a humanized monoclonal anti-E/P-selectin neurovascular protective strategy in a blinded placebocontrolled trial of nonhuman primate stroke. Circ Res. 2002;91(10):907-914.

47. Zhang JH, Badaut J, Tang J, Obenaus A, Hartman R, Pearce WJ. The vascular neural network--a new paradigm in stroke pathophysiology. Nat Rev Neurol. 2012;8(12):711-716.

48. Meffert MK, Chang JM, Wiltgen BJ, Fanselow MS, Baltimore D. NF-kappa B functions in synaptic signaling and behavior. Nat Neurosci. 2003;6(10):1072-1078.

49. Liu Z, Han G, Cao Y, Wang Y, Gong H. Calcium/calmodulin-dependent protein kinase II enhances metastasis of human gastric cancer by upregulating nuclear factor- $\mathrm{kB}$ and Akt-mediated matrix metalloproteinase-9 production. Mol Med Rep . 2014;10(5):2459-2464

50. Chai S, et al. $\mathrm{Ca}(2+)$ /calmodulin-dependent protein kinase IIgamma, a critical mediator of the NF-kappaB network, is a novel therapeutic target in non-small cell lung cancer. Cancer Lett. 2014;344(1):119-128.

51. Kim JE, Kim SY, Lim SY, Kieff E, Song YJ. Role of Ca2+/calmodulin-dependent kinase II-IRAK1 interaction in LMP1-induced NF-kappaB activation. Mol Cell Biol. 2014;34(3):325-334.

52. Maubach G, Sokolova O, Wolfien M, Rothkotter HJ, Naumann M. Ca2+/calmodulin-dependent kinase II contributes to inhibitor of nuclear factor-kappa B kinase complex activation in Helicobacter pylori infection. Int J Cancer. 2013;133(6):1507-1512.

53. Singh MV, Anderson ME. Is CaMKII a link between inflammation and hypertrophy in heart? J Mol Med (Berl). 2011;89(6):537543.

54. He BJ, et al. Oxidation of CaMKII determines the cardiotoxic effects of aldosterone. Nat Med. 2011;17(12):1610-1618.

55. Luo M, et al. Diabetes increases mortality after myocardial infarction by oxidizing CaMKII. J Clin Invest. 2013;123(3):12621274.

56. Swaminathan PD, et al. Oxidized CaMKII causes cardiac sinus node dysfunction in mice. J Clin Invest. 2011;121(8):3277-3288.

57. Purohit $\mathrm{A}$, et al. Oxidized $\mathrm{Ca}(2+)$ /calmodulin-dependent protein kinase II triggers atrial fibrillation. Circulation. 2013;128(16):1748-1757.

58. Wagner S, et al. Reactive oxygen species-activated $\mathrm{Ca} /$ calmodulin kinase IIdelta is required for late I(Na) augmentation leading to cellular Na and Ca overload. Circ Res. 2011;108(5):555-565.

59. Ho HT, et al. Ryanodine receptor phosphorylation by oxidized CaMKII contributes to the cardiotoxic effects of cardiac glycosides. Cardiovasc Res. 2014;101(1):165-174.

60. Zhu LJ, et al. Oxidative activation of the $\mathrm{Ca}(2+)$ /calmodulin-dependent protein kinase II (CaMKII) regulates vascular smooth muscle migration and apoptosis. Vascul Pharmacol. 2014;60(2):75-83.

61. Scott JA, et al. The multifunctional Ca2+/calmodulin-dependent kinase II regulates vascular smooth muscle migration through matrix metalloproteinase 9. Am J Physiol Heart Circ Physiol. 2012;302(10):H1953-1964.

62. Sanders PN, et al. CaMKII is essential for the proasthmatic effects of oxidation. Sci Transl Med. 2013;5(195):195ra197.

63. Pellicena P, Schulman H. CaMKII inhibitors: from research tools to therapeutic agents. Front Pharmacol. $2014 ; 5: 21$.

64. Coultrap SJ, Vest RS, Ashpole NM, Hudmon A, Bayer KU. CaMKII in cerebral ischemia. Acta Pharmacol Sin. 2011;32(7):861872 .

65. Moskovitz J, Bar-Noy S, Williams WM, Requena J, Berlett BS, Stadtman ER. Methionine sulfoxide reductase (MsrA) is a regulator of antioxidant defense and lifespan in mammals. Proc Natl Acad Sci U S A. 2001;98(23):12920-12925.

66.Longa EZ, Weinstein PR, Carlson S, Cummins R. Reversible middle cerebral artery occlusion without craniectomy in rats. Stroke. 1989;20(1):84-91.

67. Zhang R, et al. Calmodulin kinase II inhibition protects against structural heart disease. Nat Med. 2005;11(4):409-417.

68. Dhanesha N, Ahmad A, Prakash P, Doddapattar P, Lentz SR, Chauhan AK. Genetic ablation of extra domain A of fibronectin in hypercholesterolemic mice improves stroke outcome by reducing thrombo-inflammation. Circulation. 2015;132(23):22372247.

69. Sanlioglu S, et al. Lipopolysaccharide induces Rac1-dependent reactive oxygen species formation and coordinates tumor necrosis factor-alpha secretion through IKK regulation of NF-kappa B. J Biol Chem. 2001;276(32):30188-30198.

70. van Beijnum JR, Rousch M, Castermans K, van der Linden E, Griffioen AW. Isolation of endothelial cells from fresh tissues. Nat Protoc. 2008;3(6):1085-1091.

71. Jin H, et al. Endothelial PPAR-gamma protects against vascular thrombosis by downregulating P-selectin expression. Arterioscler Thromb Vasc Biol. 2015;35(4):838-844.

72. Dayal S, et al. Paradoxical absence of a prothrombotic phenotype in a mouse model of severe hyperhomocysteinemia. Blood. 2012;119(13):3176-3183. 